\title{
The Baby Boom: Predictability in House Prices and Interest Rates
}

\author{
Robert F. Martin
}

November 2005

\begin{abstract}
This paper explores the baby boom's impact on U.S. house prices and interest rates in the post-war $20^{\text {th }}$ century and beyond. Using a simple Lucas asset pricing model, I quantitatively account for the increase in real house prices, the path of real interest rates, and the timing of low-frequency fluctuations in real house prices. The model predicts that the primary force underlying the evolution of real house prices is the systematic and predictable changes in the working age population driven by the baby boom. The model is calibrated to U.S. data and tested on international data. One surprising success of the model is its ability to predict the boom and bust in Japanese real estate markets around 1974 and 1990.
\end{abstract}

Keywords: asset pricing, yield curve, great moderation.

JEL Codes: E21, E31, G12, R21

${ }^{*}$ The author is an economist in the Division of International Finance, Board of Governors of the Federal Reserve System. The views expressed in this paper are solely the responsibility of the author and should not be interpreted as reflecting the views of the Board of Governors of the Federal Reserve System or of any person associated with the Federal Reserve System. I would like to thank Sanjay Chugh, Morris Davis, Linda Kole, Thomas Tallarini, Brian Doyle, Jon Faust, and Sylvain Leduc. Correspondence should be addressed to: Robert F. Martin (robert.f.martin@frb.gov), Board of Governors of the Federal Reserve System, Washington DC 20551, USA. 


\section{Introduction}

This paper explores the extent to which the baby boom has impacted U.S. house prices and interest rates over the latter half of the $20^{\text {th }}$ century. Without question, the baby boom has had a direct and large impact on the dynamics of the U.S. age profile. These dynamics have manifested themselves in changes to the proportion of the population that is of working age. The boomers entered the labor force en masse between 1967 and 1973 and, over the subsequent 35 years, they increased both the size and the growth rate of the potential labor force. The baby boomers are now about to leave the workforce. As they retire, the size of the working age population will fall as will output per person.

These changes in the working age population and the associated impact on output have had and will continue to have a first order effect on house prices and interest rates in the United States. This paper builds on the intuition of the well known paper by Mankiw and Weil (1988). That paper predicted that the baby boom would lead to a peak in house prices in 1989 (they were right) and then to a large permanent fall in the real price of housing from that point forward (obviously wrong). The intuition for this result is simple. If households exhibit hump-shaped demand for housing over the life-cycle and if housing is relatively difficult to build, then house prices should exhibit a peak at the time that the baby boomers reach their peak demand and should decline as the boomer's demand for housing wanes. The obvious gulf between their predictions and the increases in house prices between 1995 and the present have caused many to dismiss both the Mankiw and Weil paper and the impact of the baby boom on house prices in toto.

This paper will resurrect their intuition. Mankiw and Weil missed the upturn only because they worked in a partial equilibrium environment and over the course of the 1990s general equilibrium effects began to dominate the contemporaneous demand effects. In other words, they neglected both the impact of discount rates on house prices and the impact of the baby boom on the discount rate. By working in a structural model, this paper is able to consider the general equilibrium effects without neglecting the demand effects which are so important in the work of Mankiw and Weil. Indeed, I will show that, if the interest rate effect is shut down in my model, the model will replicate the predictions of Mankiw and Weil.

In this paper, the baby boom impacts house prices through demand effects which are very similar to those hypothesized by Mankiw and Weil; demand for housing is high when the working age population is

large relative to the total population. However, this paper achieves a very different price path than that of 
Mankiw and Weil because the baby boom also affected interest rates and interest rates impact house prices.

In order to gain a quantitative idea of the magnitude of the effect of the baby boom on house prices, I develop a general equilibrium model which takes as input an exogenous demographic structure. Using a parsimonious and standard Lucas asset pricing framework, the model demonstrates that the demographic profile in the United States is a likely driver of both house prices and interest rates in the post-war era. In this paper, changes in the size of the working age population determine the labor input into a neoclassical production function. The model takes as given the endowment of capital, labor, and the stock of housing. As I work in an endowment economy, the model will not replicate the time series of capital accumulation - neither business nor residential. Since both of these stocks are assumed fixed, the model also misses the increase in consumption of both goods and housing services observed in the data. However, the model exactly replicates the increase in the ratio of consumption of goods and services to the consumption of housing services as reported in the National Income and Product Accounts. That is, the ratio of consumption to housing services increases by 18 percent in both the model and in the NIPA data over the period 1974 to $2004 .^{1}$

When the size of the working age population is temporarily high as it is now, output is temporarily high and households wish to transfer assets to the future. Because ability to do so is limited ${ }^{2}$, there is upward pressure on real asset prices - house prices rise, interest rates fall. ${ }^{3}$ The increase in house prices occurs now despite the certain knowledge that once the baby boomers retire real house prices will fall.

The model is calibrated to replicate low-frequency U.S. house price movements between 1963 and 2005. Only two parameters of the model are used in the calibration - the elasticity of intertemporal substitution and the elasticity of intratemporal substitution. The first objective of the calibration is to exactly match the increase in house prices over the period 1963 to 2005 . The second objective is to match the low-frequency

\footnotetext{
${ }^{1}$ The dates for the comparison are chosen to include the dates for which the baby boomers were fully incorporated into the work force. It is worth noting as well that the increase in relative consumption is not calibrated but rather is an implication of holding capital and productivity fixed while adjusting the labor input to replicate the impact of the baby boom.

${ }^{2}$ Any individual agent can transfer output over long periods of time by trading long-lived bonds. Thirty year bonds exist and exhibit fairly liquid markets. However, to undo the effects in the model real output must be physically transferred from today to the future. As the demographic shocks discussed in this paper occur over 30 to 50 year intervals, it is difficult to think of a real asset capable of making this transformation. Think of real capital and assume it depreciates at a mere 5 percent per year. Almost 80 percent of the capital is consumed by depreciation over the 30 year period. On a discounted basis over 95 percent of the capital is eroded. It is in this sense, that the ability to transfer assets to the future is limited.

${ }^{3}$ In actuality, whether or not house prices rise or fall in response to a future fall in output is parameter dependent. I show that this is true if and only if the cross-derivative between consumption of goods and consumption of housing is negative. For CES utility, this implies that the elasticity of intertemporal substitution must be less than the elasticity of intratemporal substitution. It turns out that this is the same requirement for house prices to fall when interest rates rise.
} 
swings in house prices. House prices have exhibited several cycles over the past 45 years and the goal of this paper is to replicate the timing and amplitude of these cycles using only demographics as an exogenous input to the model. The model is very successful at matching the timing of the housing cycle. With the exception of the 1973 peak in house prices, the model matches every peak in the data as well as every trough. While the model does quite well in matching the overall increase in house prices over time, it does not replicate the amplitude of the peaks and troughs. ${ }^{4}$ This model is the first model to my knowledge that is capable of matching each of the turning points in the data using a unified explanation. ${ }^{5}$

Without changing the parameters of the model, I test the model's ability to replicate the pattern of long-term real interest rates. ${ }^{6}$ Ignoring high frequency movement in the real rate, the model is consistent with interest rates over the period 1950 to 1972 during which interest rates rose and then fell and over the period 1990 to 2005 during which interest rates fell. In the intervening period, the model interest rate is too high relative to the data in the 1970s and too low relative to the data in the early 1980s. To restate this result, using the parameters which are designed to replicate house prices, the model exactly matches long-term interest rates for 37 of the past 55 years.

While the model misses the measured level of real rates in the 1970s, there are some interesting aspects of the nominal yield curve, in this time period, which are echoed in the real yield curve in the model. During this period, the nominal yield curve is consistently upward sloping. The common interpretation of this result is that agents had embodied large inflation expectations into the yield curve throughout the Fisher effect (Piazzesi and Schneider (2005)). In this model, the real yield curve is upward sloping. In the early 1970s, short rates are declining and long rates are increasing as they incorporate the increases in output which occur over the next 35 years.

The question remains "How rational do agents have to be in order to incorporate the output increases observed in the 1990s into the price of bonds being traded in the 1970s?" Do the agents need to have a

\footnotetext{
${ }^{4}$ Conditioning on observed productivity shocks would improve the fit of the model. Alternatively, a model with endogenous collateral constraints as in Lustig and Van Nieuwerburgh (20050 would likely improve the ability of the model to replicate the amplitude of he swings in house prices. In this model, the collateral constraints would serve as an accelerator (see Campbell and Hercowitz (2004)).

${ }^{5}$ Of course, researchers have been able to match the individual peaks and by extension match every peak using a unique explanation for each episode (see Ahearne et al. 2005). The common explanations are as follows: 1969 - the expansion associated with the Vietnam war; 1973 - housing as a hedge against inflation; 1979 - change in the U.S. tax code; 1989 expansion of bank loans; Current - steady low inflation brought about by improved monetary policy.

${ }^{6}$ Long-term real interest rates are defined as 10 year treasury yields adjusted for inflation expectations. For the period 1950 through 1982, I use a backward looking two-year moving average of inflation to proxy for inflation expectations. From 1982 forward, I use the survey of professional forecasters available from the Philadelphia Federal Reserve.
} 
demographic model like the one presented in this paper in order to anticipate the change in output? The answer is no. Individual agents simply looks forward to their own path of lifetime labor income. The agents in the model know their life time working hours and realize that their highest output years are yet to come. They realize that in the future their own household output per person will rise (their children becoming adults). Therefore, each agent wishes to borrow against these future increases in wealth. Unfortunately for them, the shock that they face turns out to be aggregate - their cohort goes to the bond market with them and interest rates rise. This is simply the flip side of why interest rates are low now.

One of the most surprising results of this paper is its ability to replicate the decline in output volatility in 1984. The volatility in output implied by our model falls by half in the post-1984 world. McConnell et al. (1999) identify a decline in the volatility of U.S. real GDP in 1984. This decline has been attributed alternatively to improved monetary policy (Clarida et al (2000)), improved business practices (McConnell et al. (1999), improved mortgage markets associated with regulation Q (Dynan et al (2005), or simply to a reduction in the volatility of macroeconomic shocks (Stock and Watson (2003)). The demographic model has none of these channels, implying that the good luck noted by Ahmed et al (2002) can simply be named predictable demographic changes. As the baby boom moderated so did the economy.

While it is a success in itself to match both house prices and interest rates in a such a parsimonious model, we further test the model's ability to match house prices in other industrialized countries. I test the model on data for the United Kingdom, Japan, and Ireland. The model succeeds in each case in matching both the trend in house prices and most of the major peaks in each country. Japan is the most remarkable case.

Between 1970 and 2005, Japanese real house prices exhibited peaks in 1974 and 1990. Since 1990, real house prices have fallen around 34 percent. The sharp increase in real estate prices in the 1980s followed by a fifteen-plus year fall in prices has led many to refer to 1980s Japan as the original bubble economy (Bayoumi and Collyns (2003)). This simple model, using Japanese demographic data, successfully predicts the 1974 and the 1990 house price peaks. Strikingly, the model also predicts a 30 percent decline in real house prices over the fifteen years following the 1990 peak.

The paper proceeds as follows. In the next section, I outline previous work on the link between asset prices and demographics. In section 3, the economy is presented and the two key asset pricing equations are derived. Section 4 outlines the key theoretical properties of the model. This section derives the link 
between interest rates and house prices. In section 5 , the price responses of the model are simulated in order to give a quantitative feel for the theoretical results given in section 4 . Section 6 inputs the baby boom into the model and calibrates the model to U.S. house prices. Section 7 gives the results of the calibrated model. Section 8 test the model on international data. Finally, I conclude.

\section{Relationship to Previous Work}

\subsection{Baby Boom and Asset Prices}

A number of previous studies have attempted to uncover the relationship, if it exists, between asset prices and the baby boom. These papers have met with only limited success. Almost all of these papers have focused on equity prices ${ }^{7}$ and almost without exception these papers have attempted to exploit life-cycle properties of savings and investment behavior. My primary concern with exploiting the life-cycle properties observed in the data is that it is not known a priori whether these changes are fundamental or whether they themselves are induced by the out-of-equilibrium dynamics. Indeed it might be argued that even institutional structures such as the social pension schemes have been maintained only because the baby boom has kept their cost relatively low. A different population age-profile would potentially have very different impacts on asset prices and hence would produce very different cohort behavior. It is with this concern in mind that I shut down such effects in the model.

Porterba (2004) offers a survey of many of these models. Abel (2001, 2003) shows in an over-lapping generations model that a baby boom followed by a baby bust reduces the life-time rate of return for the baby boom cohort. The results are sensitive to the specification of the bequest motive, which implies the results are quite sensitive to the specification of the life-cycle properties of consumption. ${ }^{8}$ Yoo (1994) incorporates the baby boom into a model of international capital flows. Brooks (2002) develops a general equilibrium overlapping generations model in which the return to capital and the return to bonds varies over the baby boom. Porterba $(2001,2003,2004)$ finds little evidence of a robust empirical relationship between asset returns and the baby boom. Rios-Rull (2001) finds that the implications of the baby boom on asset prices is quite sensitive to the assumed steady state properties of the model. Storesletten (2003) offers a model

\footnotetext{
${ }^{7}$ An important exception to this is the study conducted by Mankiw and Weil (1988) which is discussed in the next sub-section.

${ }^{8}$ De Nardi (2001) shows in her dissertation and in subsequent work with Cagetti (2005) that the savings properties of over-lapping generation economies are quite sensitve to the bequest motive.
} 
similar in spirit to that of Yoo. In his model, Storesletten finds that changing immigration policy can offset the impact of the baby boom.

\section{The Economy}

The economy consists of a single representative agent. While more complicated demographics could easily have been implemented in the model, this framework ensures the absence of the life-cycle type savings behavior which is the focus of so much of the previous work. That is, the dynamics in this model are not driven by dissaving on the part of some sub-set of agents but rather by aggregate fluctuations in output. The representative agent framework will also allow closed-form solutions for the pricing equations. The closed-form solutions, in turn, give very clean theoretical results.

The baby boom will be modeled as changes in the agent's endowment of time. The amount of time that the agent has to work in any period represents the percentage of the population which is of working age in a period. In other words, changes in the size of the working age population relative to the total population are modeled by adjusting the endowment of time between 0 and 1 . A value of 1 implies that the entire population is of working age; likewise, a value of zero implies the population is non-productive. ${ }^{9}$ Empirically, values for this number have varied between near 0.78 in 1972 to around 0.95 in 2005 for the United States. As the percent of the working age population exactly determines output in this economy, variation in the size of the working age population will map directly into changes in endowment of the consumption good.

One aspect of the economy which is significant and which the current exercise forgoes is endogenous capital accumulation. This omission is important as allowing households the ability to smooth consumption over time mitigates the effects of output declines. However, there are several reasons why this omission is not as restrictive as in many previous papers. The effects of capital accumulation on prices are not as straightforward in this model as in a standard model as capital interacts in a subtle manner with house prices. That is, accumulation of capital today increases output of market goods today which tends to raise house prices.

Further, I argue that most inter-generational savings is of second-order importance. The effects drawn

\footnotetext{
${ }^{9}$ In a single household, the thought experiment is as follows: A couple with no children has time endowment of 1 . A couple with three children (all below working age) was a time endowment of $2 / 5$. A couple with three working children has a time endowment of $5 / 5$. The same household with two retired parents has a time endowment of $3 / 5$.
} 
upon here are not driven by transfers from young to old which have no effect on economy-wide consumption. Rather, the effects exploited in this paper are driven by the aggregate economy's inability to transfer consumption between today and tomorrow. In the model presented here, the shocks occur over 20 to 50 year time periods and are more-or-less uninsurable. The shocks have real effects beyond what would be mitigated by inter-generational transfers. Note, that independent of the level of the capital stock, upon the retirement of the baby boomers, labor input and therefore output fall.

The model also ignores international capital flows. That is, the model relies on a closed economy assumption. This assumption is important as differing demographic structures across the world may allow international risk sharing. However, although there are difference in the demographic structures across countries in the industrialized world these differences are actually quite small. Given the long-lived nature of the shocks and the similarity in shocks across countries risk sharing may not be possible. Risk sharing between the industrialized world and the developing world may be limited by the development of financial markets in the latter or by the omnipresent risk of sovereign default in much of the developing world.

\subsection{Endowment}

The agent is endowed with a fixed amount of time which may change from period-to-period; however, the time path for the labor endowment is known with probability one from time zero. That is, while the time endowment may shift over time, the agent has perfect foresight over these changes.

The agent is endowed with a unit of housing. This assumption is intended to mirror an assumption in the data section in which the stock of housing per person is held constant. The critical assumption is that the stock of housing is not a function of the time endowment of the agent.

\subsection{Technology}

The model is a simple two sector model. One sector produces consumption goods taking labor as input. Labor is transformed to efficiency units through a productivity parameter. The other sector (thought of as the home sector) takes the stock of housing capital, scales it by a productivity factor, and produces housing services. Production of housing services does not require time as an input. Output from neither sector is storable, although housing capital itself is thought of as perfectly durable. Productivity is assumed constant in both sectors. 


\subsection{The Agent's Problem}

The representative agent chooses sequences of consumption, $c$, and housing capital, $H_{t+1}$, and zero-net supply bonds, $A_{t+1}$, in order to maximize a time additively separable utility function as follows:

$$
\begin{aligned}
\max _{c_{t}, H_{t+1}, A_{t+1}} & \sum_{t=0}^{\infty} \beta^{t} U\left(c_{t}, h_{t}\right) \\
& s t \\
c_{t}+p_{t} H_{t+1}+A_{t+1} & =Z_{t}^{m} N_{t}+R_{t} A_{t}+p_{t} H_{t} \\
h_{t} & =Z_{t}^{h} H_{t+1}
\end{aligned}
$$

$N_{t}$ is the time $t$ endowment of time. $N_{t}$ is normalized to lie on the interval between 0 and 1 . The implicit price of the zero-net supply bonds is $\frac{1}{R_{t}}$, and the price of housing capital is $p_{t}$. $Z_{t}^{h}$ and $Z_{t}^{m}$ are productivity factors on housing capital and labor respectively. The parameter $Z_{t}^{h}$ may be thought of as a parameter which maps stocks of housing into flows of housing services. Housing services, $h_{t}$, today are produced by the stock of housing denoted $t+1$. This assumption is a timing convention and is without loss of generality. The agent discounts future utility at rate $\beta$.

Prices adjust such that the following equilibrium conditions are satisfied

$$
\begin{aligned}
c_{t} & =Z_{t}^{m} N_{t} & \forall t \\
H_{t+1} & =H_{t} & \forall t \\
A_{t} & =0 & \forall t
\end{aligned}
$$

The equilibrium conditions make it clear that the agent may not transform market output to home output nor may the agent transform home output to market output. There is no storage. 
The first order conditions are as follows:

$$
\begin{aligned}
c_{t} & : \quad U_{c}\left(c_{t}, h_{t}\right)=\lambda_{t} \\
H_{t+1} & : \quad \lambda_{t} p_{t}=U_{h}\left(c_{t}, h_{t}\right) Z_{t}^{h}+\beta \lambda_{t+1} p_{t+1} \\
A_{t+1} & : \quad \lambda_{t}=\beta R_{t+1} \lambda_{t+1}
\end{aligned}
$$

where $\lambda_{t}$ is the Lagrange multiplier on the time $t$ budget constraint. One may solve for $p_{t}$ by finding a solution to the difference equation implied by the first order condition for $H_{t+1}$. After substituting for $\lambda_{t}$ from the first order condition for $c_{t}$, the solution is found by iterating forward on $p$ as follows:

$$
\begin{aligned}
p_{t} & =\frac{U_{h}\left(c_{t}, h_{t}\right)}{U_{c}\left(c_{t}, h_{t}\right)} Z_{t}^{h}+\beta \frac{U_{c}\left(c_{t+1}, h_{t+1}\right)}{U_{c}\left(c_{t}, h_{t}\right)} p_{t+1} \\
p_{t} & =\frac{U_{h}\left(c_{t}, h_{t}\right)}{U_{c}\left(c_{t}, h_{t}\right)} Z_{t}^{h}+\beta \frac{U_{c}\left(c_{t+1}, h_{t+1}\right)}{U_{c}\left(c_{t}, h_{t}\right)}\left\{\frac{U_{h}\left(c_{t+1}, h_{t+1}\right)}{U_{c}\left(c_{t+1}, h_{t+1}\right)} Z_{t+1}^{h}+\beta \frac{U_{c}\left(c_{t+2}, h_{t+2}\right)}{U_{c}\left(c_{t+1}, h_{t+1}\right)} p_{t+2}\right\} \\
p_{t} & =\frac{U_{h}\left(c_{t}, h_{t}\right)}{U_{c}\left(c_{t}, h_{t}\right)} Z_{t}^{h}+\beta \frac{U_{c}\left(c_{t+1}, h_{t+1}\right)}{U_{c}\left(c_{t}, h_{t}\right)}\left\{\frac{U_{h}\left(c_{t+1}, h_{t+1}\right)}{U_{c}\left(c_{t+1}, h_{t+1}\right)} Z_{t+1}^{h}+\beta \frac{U_{c}\left(c_{t+2}, h_{t+2}\right)}{U_{c}\left(c_{t+1}, h_{t+1}\right)}\{\ldots\}\right\} \\
p_{t} & =\sum_{s=0}^{\infty} \beta^{s} \frac{U_{c}\left(c_{t+s}, h_{t+s}\right)}{U_{c}\left(c_{t}, h_{t}\right)} \frac{U_{h}\left(c_{t+s}, h_{t+s}\right)}{U_{c}\left(c_{t+s}, h_{t+s}\right)} Z_{t+s}^{h}
\end{aligned}
$$

The first term in the last line, $\beta^{s} \frac{U_{c}\left(c_{t+s}, h_{t+s}\right)}{U_{c}\left(c_{t}, h_{t}\right)}$, is simply the agent's effective rate of time discount between period $t$ and period $t+s$. This term is often referred to as the pricing kernel and is the factor used to discount the payoff of any future return. ${ }^{10}$ The second term in the last line, $\frac{U_{h}\left(c_{t+s}, h_{t+s}\right)}{U_{c}\left(c_{t+s}, h_{t+s}\right)} Z_{t+s}^{h}$, can be thought of as the dividend payout from housing. The flow value of housing is the marginal utility of housing evaluated at the stock of housing scaled by the marginal utility of consuming evaluated at the endowment of consumption. Housing is not special in this model. The price of a consul bond with dividend flow equal to $\frac{U_{h}\left(c_{t+s}, h_{t+s}\right)}{U_{c}\left(c_{t+s}, h_{t+s}\right)} Z_{t+s}^{h}$ would perfectly commove with the price of housing.

Interest rates evolve according to the following equation:

$$
\frac{1}{R_{t+s}}=\beta^{s} \frac{U_{c}\left(c_{t+s}, h_{t+s}\right)}{U_{c}\left(c_{t}, h_{t}\right)}=\prod_{j=0}^{s} \beta \frac{U_{c}\left(c_{t+j+1}, h_{t+j+1}\right)}{U_{c}\left(c_{t+j}, h_{t+j}\right)}
$$

where $R_{t+s}$ denotes the total rate of return between period $t$ and $t+s$. The expectations hypothesis for the

\footnotetext{
${ }^{10}$ The pricing kernel is defined in terms of the marginal utility of numeraire consumption. Below in the simulation section, a new pricing kernel is defined, by exploiting the specific functional form, over total consumption.
} 
term structure of interest rates holds exactly in this model, i.e. long real rates are simply the product of one period returns.

Combining the equation for house prices and the equation for interest rates, we derive the commonly used expression for the price of housing.

$$
\begin{aligned}
p_{t} & =\sum_{s=0}^{\infty} \frac{1}{R_{t+s}} R E N T_{t+s} \\
R E N T_{t+s} & \equiv \frac{U_{h}\left(c_{t+s}, h_{t+s}\right)}{U_{c}\left(c_{t+s}, h_{t+s}\right)} Z_{t+s}^{h}
\end{aligned}
$$

The price of housing in period $t$ is the present discounted value of rents, where the appropriate discount rate is the real interest rate. This equation is often misused and is the equation by which the statement "housing is under-responsive to interest rates" (Campbell et al (2005)) is made. If we hold rents constant, then this equation implies that prices must respond one-for-one with any permanent change in interest rates. Think of the example in which we simply reduce the entire term structure by a factor $\theta$. Then

$$
p_{t}^{*}=\sum_{s=0}^{\infty} \frac{1}{\theta R_{t+s}} R E N T_{t+s}=\frac{1}{\theta} p_{t}
$$

the price level simply adjusts by the factor $\frac{1}{\theta}$. Since measured real rates appear extremely persistent (Campbell et al (2005)), any measured change in the real rate would be expected to have a large effect on the price level. The fact that this is not true in the data leads to the under-responsive statement above. However, this thought experiment is based on a false premise - that we can change interest rates and not the flow of rents. In this class of models, house prices and interest rates are driven by the same underlying fundamentals - the time series of housing and goods consumption. Changes in the path of either will, in general impact both assets. In section 4 below, I show that only in the case where $U_{h c}$ is zero can this experiment be reliably conducted. 


\section{Theoretical Analysis}

In this section, the relationship between prices interest rates and output at all horizons is established. ${ }^{11}$ Perhaps the most important result in this section is Corollary 2. Conventional wisdom based on equation 4 is that house prices and interest rates must have an inverse relationship. That is, any increase in the interest rate must lower house prices. This statement turns out to be parameter dependent. Because any change in interest rates is, in general, associated with a change in rents, this statement is only true if the cross derivative between housing and consumption is negative. This result is important because it shows us that the intuition which leads to equation 5 is fatally flawed.

The response of interest rates to a change in future consumption is straightforward and standard. Agents would like to smooth consumption. Because they are unable to do so, bond prices must adjust such that the agent is content with his current endowment.

Proposition 1 A fall in future goods consumption at date $s$ decreases interest rates for bonds paying off in period $s$ but leaves other interest rates unchanged: $\frac{\partial R_{t+j}}{\partial c_{t+s}} \leq 0$ with equality if and only is $j=s$.

Proof. This result is straight forward from the bond pricing equation or from the fact that the expectations hypothesis holds in this model. The payoff of a bond paying off in period $j$ is affected by changes in allocations in those periods only. That is only for the period to which the agent would like to reallocate consumption does the interest rate structure change. This is immediate from the formula $\frac{1}{R_{t+s}}=\beta^{s} \frac{U_{c}\left(c_{t+s}, h_{t+s}\right)}{U_{c}\left(c_{t}, h_{t}\right)}$.

A direct implication of the above theorem is that changes in future consumption move the term structure of interest rates in a very specific manner. The following corollary shows that the yield curve becomes generally flatter only for changes in consumption which occur over long periods of time. That is, short term changes in consumption impact interest rates at specific horizons; therefore, a flatter yield curve consumption implies lower consumption at all long dates relative to all short dates.

Corollary 1 The yield curve becomes flatter (steeper) between bonds dated $s-k$ and bonds dated $s+j$ if consumption falls (increases) at all dates $s+j: \frac{\partial\left(R_{t+s+j}-R_{t+s-j}\right)}{\partial c_{t+s}}<0 \forall j>0, k>0$.

\footnotetext{
${ }^{11}$ For ease of exposition, the short cut of considering changes in prices to changes in consumption is used. However, since consumption and output are isomorphic this short cut is without loss of generality.
} 
Proof. The result follows from the above theorem. Since $\frac{\partial R_{t+j}}{\partial c_{t+s}} \leq 0$ with equality if and only if $c_{j}<c_{s}$, then $\frac{\partial\left(R_{t+s+j}-R_{t+s-j}\right)}{\partial c_{t+s}}=\frac{\partial R_{t+s+j}}{\partial c_{t+s}}<0$ if and only if $c_{j}<c_{s}$.

Whereas the impact of changes in consumption on interest rates is immediate, the sign of the change in house prices today in response to a future fall in consumption is ambiguous. The reason for the ambiguity is because housing is a durable good and hence its price is impacted by the discount rate but it is also a consumption good and hence its price is impacted by its relative scarcity. Take the case of a fall in future consumption. The fall in consumption lowers interest rates which puts upwards pressure on house prices. However, the fall in consumption also makes housing relatively plentiful which puts downward pressure on prices. The relative strength of these two forces determines whether prices rise or fall in response to changes in future consumption. As the next proposition shows, the relative strength of the two affects is determined by the sign of the cross-derivative, $U_{h c}$.

Proposition 2 The real price of housing rises (falls) in response to a fall (rise) in future goods consumption if and only if the cross-derivative between consumption of goods and the consumption of housing is negative: $\frac{\partial p_{t}}{\partial c_{t+s}} \leq 0 \Longleftrightarrow U_{h c} \leq 0$.

Proof. This result is straightforward from differentiation of the pricing equation for housing. We have after simplifying $p_{t}=\sum_{s=0}^{\infty} \beta^{s} \frac{U_{h}\left(c_{t+s}, h_{t+s}\right)}{U_{c}\left(c_{t}, h_{t}\right)} Z_{t+s}^{h}$. Differentiating with respect to $c_{t+s}$, we have $\frac{\partial p_{t}}{\partial c_{t+s}}=$ $\beta^{s} \frac{U_{h c}\left(c_{t+s}, h_{t+s}\right)}{U_{c}\left(c_{t}, h_{t}\right)} Z_{t+s}^{h} \Longrightarrow \operatorname{sign}\left(\frac{\partial p_{t}}{\partial c_{t+s}}\right)=\operatorname{sign}\left(U_{h, c}\left(c_{t}, h_{t}\right)\right)$.

The last result occurs because there is a direct and an indirect effect. Consumption falls so we wish to move consumption to that period on the other hand the relative price of consumption in that period rises so we would like to move more consumption to that period in the form of housing. Our ability to make this trade-off then relies on relative elasticities. The same effect can be seen in examining the response of interest rates to changes in $h_{t+s}$. In this case, the interest rate effect also depends on the relative elasticities or more specifically on the sign of the cross-derivative.

Proposition 3 Interest rates rise (fall) in response to a rise (fall) in future housing consumption if and only if the cross-derivative between consumption of goods and the consumption of housing services is negative: $\frac{\partial R_{t+j}}{\partial h_{t+s}} \geq 0 \Longleftrightarrow U_{h c} \leq 0$. 
Proof. Again the equation for interest rates is

$$
\begin{aligned}
R_{t+s} & =\frac{1}{\beta^{s}} \frac{U_{c}\left(c_{t}, h_{t}\right)}{U_{c}\left(c_{t+s}, h_{t+s}\right)} \\
\frac{\partial R_{t+j}}{\partial h_{t+s}} & =\frac{1}{\beta^{s}} \frac{U_{c}\left(c_{t}, h_{t}\right)}{\left(U_{c}\left(c_{t+s}, h_{t+s}\right)\right)^{2}}\left(-U_{c h}\left(c_{t+s}, h_{t+s}\right)\right)
\end{aligned}
$$

Since the first two terms of the derivative are always positive, $\operatorname{sign}\left(\frac{\partial R_{t+j}}{\partial h_{t+s}}\right)=-\operatorname{sign}\left(U_{c h}\left(c_{t+s}, h_{t+s}\right)\right)$.

It has long been assumed in the empirical and theoretical literature that housing and interest rates should have an inverse relationship. The last two theorems show that this does not have to be the case. Indeed the previous propositions show that the change in interest rates and prices will depend on the both the sign of $U_{c h}$ and on whether interest rates and house prices are responding to future or contemporaneous movements and whether the movements are caused by changes in $c$ or $h$.

Corollary 2 House prices and interest rates have a weak inverse relationship if and only if the crossderivative between consumption of good and the consumption of housing is negative: $\operatorname{sign}\left(\frac{\partial R_{t+s}}{\partial x_{t+s}}\right)=$ $-\operatorname{sign}\left(\frac{\partial p_{t}}{\partial x_{t+S}}\right) \Longleftrightarrow U_{c h}<0 x \in\{c, h\}$

Proof. The result is checked first for $x=c$ and then for $x=h$. If $x=c$, above it was shown that $\frac{\partial R_{t+j}}{\partial c_{t+s}}>0$ but $\frac{\partial p_{t}}{\partial c_{t+s}} \leq 0 \Longleftrightarrow U_{h c} \leq 0$. Hence, for the case of changes in future consumption the result is shown. If $x=h, \frac{\partial p_{t}}{\partial h_{t+s}}=\beta^{s} \frac{U_{h h}\left(c_{t}, h_{t}\right)}{U_{c}\left(c_{t}, h_{t}\right)} Z_{t+s}^{h}<0$ but $\frac{\partial R_{t+j}}{\partial h_{t+s}} \geq 0 \Longleftrightarrow U_{h c} \leq 0$. Given the if and only if relation for both $h$ and $c$ the proof is complete.

At this point, the relationship between both interest rates and prices to changes in future consumption of housing and market goods has been established. The response of house prices to contemporaneous changes in consumption is now examined.

Condition $1 U_{c}\left(c_{t}, h_{t}\right) Z_{t}^{h}<\sum_{s=0}^{\infty} \beta^{s} U_{h}\left(c_{t+s}, h_{t+s}\right) Z_{t+s}^{h}$

Condition 1 is a statement on the relative scarcity of consumption of numeraire relative to housing consumption. If the condition holds, housing is sufficiently scarce that consuming one extra unit of housing forever is worth more than consuming an extra unit of consumption today.

\section{Proof.}


Proposition 4 House prices rise (fall) in response to a contemporaneous rise (fall) in consumption if and only if the cross-derivative between housing and consumption is negative: $\frac{\partial p_{t}}{\partial c_{t}} \geq 0 \Longleftrightarrow U_{h c} \leq 0$

Proof. Using the price of housing $p_{t}=\sum_{s=0}^{\infty} \beta^{s} \frac{U_{h}\left(c_{t+s}, h_{t+s}\right)}{U_{c}\left(c_{t}, h_{t}\right)} Z_{t+s}^{h}$ and this time differentiating with respect to $c_{t}$.

$$
\begin{aligned}
\frac{\partial p_{t}}{\partial c_{t}} & =\frac{-U_{c h}\left(c_{t}, h_{t}\right)}{U_{c}\left(c_{t} h_{t}\right)^{2}} \sum_{s=0}^{\infty} \beta^{s} U_{h}\left(c_{t+s}, h_{t+s}\right) Z_{t+s}^{h}+\frac{U_{c, h}\left(c_{t}, h_{t}\right)}{U_{c}\left(c_{t}, h_{t}\right)} Z_{t}^{h} \\
& =\frac{U_{c h}\left(c_{t}, h_{t}\right)}{U_{c}\left(c_{t}, h_{t}\right)^{2}}\left\{U_{c}\left(c_{t}, h_{t}\right) Z_{t}^{h}-\sum_{s=0}^{\infty} \beta^{s} U_{h}\left(c_{t+s}, h_{t+s}\right) Z_{t+s}^{h}\right\}
\end{aligned}
$$

Hence $\operatorname{sign}\left(\frac{\partial p_{t}}{\partial c_{t}}\right)=-\operatorname{sign}\left(U_{c h}\left(c_{t}, h_{t}\right)\right)$.

and a similar result for the response of interest rates to a contemporaneous change in housing

Proposition 5 Interest rates at any horizon s rise (fall) in response to a contemporaneous rise (fall) in housing consumption if and only if the cross-derivative between consumption of goods and the consumption of housing is positive: $\frac{\partial R_{t+s}}{\partial h_{t}} \geq 0 \Longleftrightarrow U_{h c} \geq 0$.

Proof. Using the interest rate equation for an arbitrary horizon $s, R_{t+s}=\frac{1}{\beta^{s}} \frac{U_{c}\left(c_{t}, h_{t}\right)}{U_{c}\left(c_{t+s}, h_{t+s}\right)}$, and differentiating with respect to $h_{t}$, implies $\frac{\partial R_{t+s}}{\partial h_{t}}=\frac{1}{\beta^{s}} \frac{U_{c h}\left(c_{t}, h_{t}\right)}{U_{c}\left(c_{t+s}, h_{t+s}\right)}$ once again implying $\operatorname{sign}\left(\frac{\partial R_{t+s}}{\partial h_{t}}\right)=\operatorname{sign}\left(U_{c h}\left(c_{t}, h_{t}\right)\right)$.

Implications of the model are now examined.

\section{Simulation}

In this section, we study the magnitude of the response in prices and interest rates to changes in the time path of consumption. The simple experiments given in this section will not only demonstrate how the theoretical results derived in the last section work in practice but will also pin down the potential magnitudes of changes in output on asset prices. That is, does the fact that house prices have the potential to increase in the face of a known future change in output have relevance or is the change so small as to be beneath recognition. 
The two relevant pricing equations, in terms of the CES utility function, are

$$
\begin{aligned}
p_{t} & =\sum_{s=0}^{\infty} \beta^{s}\left(\frac{\left(\gamma c_{t+s}^{\alpha}+(1-\gamma) h_{t+s}^{\alpha}\right)}{\left(\gamma c_{t}^{\alpha}+(1-\gamma) h_{t}^{\alpha}\right)}\right)^{\frac{1-\sigma-\alpha}{\alpha}} \frac{(1-\gamma) h_{t+s}^{\alpha-1}}{\gamma c_{t}^{\alpha-1}} Z_{t+s}^{h} \\
R_{t+s} & =\frac{1}{\beta^{s}}\left(\frac{\left(\gamma c_{t}^{\alpha}+(1-\gamma) h_{t}^{\alpha}\right)}{\left(\gamma c_{t+s}^{\alpha}+(1-\gamma) h_{t+s}^{\alpha}\right)}\right)^{\frac{1-\sigma-\alpha}{\alpha}} \frac{c_{t}^{\alpha-1}}{c_{t+s}^{\alpha-1}}
\end{aligned}
$$

The top equation is the price of housing and the bottom is the real interest rate. In order to ease exposition, define the function $m_{t+s}=\left(\frac{\left(\gamma c_{t+s}^{\alpha}+(1-\gamma) h_{t+s}^{\alpha}\right)}{\left(\gamma c_{t}^{\alpha}+(1-\gamma) h_{t}^{\alpha}\right)}\right)^{\frac{1-\sigma-\alpha}{\alpha}}$. Written in this manner, the discount of future payoffs changes symmetrically (modulo $\gamma$ ) to changes in $c_{t+s}$ and $h_{t+s}$ but only change in $h_{t+s}$ affect future rents. This formulation turns out to be convenient when examining the effect of changes in consumption on prices.

The model has four parameters which must be chosen $-\gamma, \alpha, \sigma, \beta$. The parameter $\gamma$ determines the share of housing consumption in utility This parameter can be adjusted to match any level of prices (see Davis and Martin 2005). ${ }^{12}$ The parameter $\beta$ is the standard time discount rate. This parameter will be set such that the real interest rate is 4 percent over any constant consumption path. The parameters $\alpha$ and $\sigma$ govern the elasticity of intratemporal substitution and the elasticity of intertemporal substitution respectively. In terms of the theoretical analysis section, it is these two parameters which govern the sign of the cross-derivative, $U_{h c}$.

As a reminder, for the CES utility function, the sign of the cross-derivative depends entirely on the sign of $(1-\sigma-\alpha)$.

$$
\operatorname{sign}(1-\sigma-\alpha)=\operatorname{sign}\left(U_{h, c}(c, h)\right)
$$

If the two types of goods are more substitutable intratemporally than intertemporally, then $(1-\sigma-\alpha)>0$ and the cross-derivative is positive, otherwise it is negative. Notice, that, since $\alpha \in(-\infty, 1)$, the crossderivative is positive only if the two goods are significantly more complementary than Cobb-Douglas utility $(\alpha=0)$.

\footnotetext{
${ }^{12}$ In the data section below, prices are typically shown as index values. The degree of freedom offered by the parameter $\gamma$ makes the indexing without loss of generality.
} 


\subsection{Permanent Fall in Consumption N Periods Ahead}

In the first experiment, the impact of a permanent fall in consumption $N$ periods in the future is examined. The fall in consumption $N$ periods in the future is revealed in period $t .{ }^{13}$ We can use summation by parts to write the pricing equation for housing in two pieces as follows:

$$
\begin{aligned}
p_{t} & =\sum_{s=0}^{N-1} \beta^{s} m_{t+s} \frac{(1-\gamma) h_{t+s}^{\alpha-1}}{\gamma c_{t}^{\alpha-1}} Z_{t+s}^{h}+\sum_{s=N}^{\infty} \beta^{s} m_{t+s} \frac{(1-\gamma) h_{t+s}^{\alpha-1}}{\gamma c_{t}^{\alpha-1}} Z_{t+s}^{h} \\
m_{t+s} & =\left(\frac{\left(\gamma c_{t+s}^{\alpha}+(1-\gamma) h_{t+s}^{\alpha}\right)}{\left(\gamma c_{t}^{\alpha}+(1-\gamma) h_{t}^{\alpha}\right)}\right)^{\frac{1-\sigma-\alpha}{\alpha}}
\end{aligned}
$$

The first term is the sum over all dates up to the event date and the second term is the sum of all dates on or after the event date. Since the above equation is the time $t$ pricing equation, the denominator of both $m_{t+s}$ and the rent term consist solely of date $t$ values implying that the denominator is the same before and after the event date.

Since consumption falls permanently at date $N$ and is unchanged between $t$ and $N, m_{t+s}$ takes on only two distinct values. It takes on value $m_{1}$ for all dates prior to the event date and value $m_{2}$ for all dates on or after the event date. Recalling that $h$ is constant by assumption, the pricing equation can be written as follows

$$
\begin{aligned}
& p_{t}=\frac{(1-\gamma) h_{t}^{\alpha-1}}{\gamma c_{t}^{\alpha-1}} Z_{t}^{h}\left\{\sum_{s=0}^{N-1} \beta^{s} m_{1}+\sum_{s=N}^{\infty} \beta^{s} m_{2}\right\} \\
& p_{t}=\frac{(1-\gamma) h_{t}^{\alpha-1}}{\gamma c_{t}^{\alpha-1}} Z_{t}^{h}\left\{\frac{1-\beta^{N}}{1-\beta} m_{1}+\frac{\beta^{N}}{1-\beta} m_{2}\right\}
\end{aligned}
$$

where the second equation uses the formula for geometric sums to arrive at a closed form solution for the time $t$ price of housing.

The formula for the price of housing is simply a weighted sum of $m_{1}$ and $m_{2}$, where the relative weights are a function of the remaining time between the current period, $t$, and the event date, $N$. As the economy approaches the event date, the weight on $m_{2}$ converges from below to $\frac{1}{1-\beta}$ and the weight on $m_{1}$ converges from above to zero. That is, the difference between consumption at date $t$ and consumption after the event

\footnotetext{
${ }^{13}$ The change in the consumption path is a zero probability event. The price path shown from date $t$ forward is exactly identical to the price path which would have occurred had the fall in consumption at date $N$ always been known. The announcement is treated as an event in this case to highlight the price jump at the announcement date.
} 
date becomes increasingly important as the event date approaches.

Whether prices rise or fall as the economy nears the event date is determined by the relative size of $m_{1}$ and $m_{2}$. If $m_{1}$ is larger than $m_{2}$, house prices will fall as $t$ approaches the event date, $N$. In this example $c_{t+N}$ is less than $c_{t}$, so $m_{1}$ will be larger than $m_{2}$ if the power $(1-\sigma-\alpha)$ is positive. That is, $m_{1}$ will be larger than $m_{2}$ if goods are more substitutable intertemporally than intratemporally (Proposition 2).

Do house prices rise or fall between periods $N-1$ and $N$. The pricing equation at date $N-1$ and $N$ are as follows

$$
\begin{aligned}
p_{N-1} & =\frac{(1-\gamma) h_{N-1}^{\alpha-1}}{\gamma c_{N-1}^{\alpha-1}} Z_{t}^{h}\left\{m_{1}+\frac{\beta}{1-\beta} m_{2}\right\} \\
p_{N} & =\frac{(1-\gamma) h_{N}^{\alpha-1}}{\gamma c_{N}^{\alpha-1}} Z_{t}^{h}\left\{\frac{1}{1-\beta}\right\}
\end{aligned}
$$

Since $\frac{(1-\gamma) h_{N}^{\alpha-1}}{\gamma c_{N}^{\alpha-1}}<\frac{(1-\gamma) h_{N-1}^{\alpha-1}}{\gamma c_{N-1}^{\alpha-1}}$ and $m_{2}$ is positive, $p_{N}$ is always less than $p_{N-1}$. House prices fall discreetly at the event date. This is true independent of assumptions on parameters. Rents fall because housing is relatively less scarce after the event date and house prices are just the discounted sum of rents. By extension, house prices are also lower after the event date than before the announcement date.

Figure 1 shows the price of housing for a specific parameterization. Prior to the announcement date, period 1, consumption of both housing and other goods are set equal to one. At date 1, the announcement that consumption of goods will fall by 30 percent at date 50 is made. Figure 4 shows the evolution of house prices from five periods before the announcement until ten periods after the event date for several different values $\alpha$. The other parameters are set as follows: $(\sigma=3, \beta=.96, \gamma=.7)$. The first vertical line demarcates the announcement date and the second vertical line demarcates the event date.

Prices rise in response to the announcement and continue to rise until the event date for all values of $\alpha$ which are greater than $-2(1-\sigma)$. When $\alpha$ is equal to -2 , price do not change until the actual event date when rents fall. For all values of $\alpha$ less than -2 , price fall steadily between the announcement date and the event date. In all cases, the price of housing falls at the event date. The fall in price occurs because at date 50 rents fall precipitously ${ }^{14}$ The important thing to take away from this simulation is that the price of

\footnotetext{
${ }^{14}$ Recall, the rental price of housing in period $t$ is given by $\frac{1-\gamma}{\gamma}\left(\frac{h_{t}}{c_{t}}\right)^{\alpha-1}$. Hence, rents are governed by $\gamma$ and $\alpha$ and the relative size of the two goods. Notice, the more negative is $\alpha$ the more rents fall at date 50 and that rents are absolutely constant until date 50 .
} 
housing can rise today even in the face of a perfectly certain fall in prices in the future.

Housing, acting effectively as a consul bond paying off in rents, is affected period-by-period between period $t$ and $N$. The interest rates on single period bonds and the term structure are however only affected at intervals over which the event occurs. Using our notation, the $s$ period interest rate is written as follows

$$
R_{t+s}=\frac{1}{\beta^{s}} \frac{1}{m_{t+s}} \frac{c_{t}^{\alpha-1}}{c_{t+s}^{\alpha-1}}
$$

For dates $t$ and $s$ less than 50, the interest rate at horizon $s$ is determined solely by $\frac{1}{\beta^{s}}$. For interest rates which cross the date $m_{t+s}$ and $\frac{c_{t}}{c_{t+s}}$ are both reduced. After date 50, the interest rate at horizon $s$ is once again governed by $\frac{1}{\beta^{s}}$ alone. Here the flattening of the yield curve is actually a kink (because of the discrete nature of the event). As we approach the event date, short rates are unaffected and long rates are lower by the factor $\frac{1}{m_{t+s}} \frac{c_{t}^{\alpha-1}}{c_{t+s}^{\alpha-1}}$. When $\alpha$ is 0.5 , this factor is 0.45 . That is interest rates are only 45 percent as large as an equivalent horizon interest rate which does not span the event date. When $\alpha$ is -0.5 , the factor drops to -0.39 . By the time $\alpha$ is -5 , the factor has dropped to $0.28 .^{15}$

\subsection{Changes in the Growth Rate of Consumption (a baby boom)}

The second experiment is designed to show how house prices behave along different consumption paths. To fix ideas, the value of $\alpha$ is set to -.05 and the value of $\sigma$ is set to 3 . This experiment is meant to demonstrate the mechanisms at work over a baby boom. To do so, consumption will be held constant for 25 years (pre-entry into workforce), allowed to grow at 1 percent per year for 25 years (the baby enters the workforce), held constant again for 25 years (not yet retired), and then fall at 0.5 percent for 25 years (the baby boom retires) before being held constant for the infinite future (back to the steady state). Figure 1a shows the results of this simulation. The solid line is the price path of housing. The dashed line is the path of rents. Recall that the path of rents is isomorphic to the path of consumption. The dashed dot line is the rent-to-price ratio for this economy.

First, note that house prices are not constant during either of the periods in which consumption is not changing. Not surprisingly given the results of the last simulation, the path of prices in influenced by future

\footnotetext{
${ }^{15}$ Note, that the response in interest rates to a fall in consumption is largely governed by the magnitude of $\sigma$. As $\sigma$ increases, the interest rate become more sensitive to changes in consumption. Of course, the responsiveness of house prices is also determined by the responsiveness of interest rates.
} 
consumption. Over the first twenty five years, the agent looks forward to the relatively good times once the baby boom enters the workforce. The relatively high interest rates imply falling house prices over this period. In the second zero consumption growth period - periods 50 through 75 - prices rise as real interest rates fall in anticipation of the baby boom's retirement. Over the period with rising consumption, the increase in house prices is almost double the increase in rents. This rise occurs because consumption is rising relative to housing raising rents and because real interest rates are falling because consumption will grow less quickly in the future. The rent-to-price ratio reaches a high of just above 4.7 in period 25 before plummeting to a low of 3.7 in year 75 . The rent-to-price ratio returns to its steady state value of 4 at the end of the sample as consumption remains constant from period 100 forward.

\section{The U.S. Baby Boom}

\subsection{Interpreting the Baby Boom in a RA Model}

The model will now be fit to the U.S. data. The model presented above is a representative agent model. In order to replicate the impact of the baby boom, the time endowment of the agent will be adjusted to match the proportion of the population which is of working age. That is, if half of the population is between the ages of 25 and 64 , the time endowment of the representative agent will be 0.5 . Notice that this assumption implies that agents who are working age are engaged in productive activity whether or not they are in the formal market sector. This view is not completely standard but is consistent with the home production literature and the human capital accumulation literature. That is if a person of working age is not in the traditional labor force then they are engaged in some type of home production (for example, a woman who quits work to raise children is producing home goods). The assumption assumes that retirees and children have zero productivity. At this time, no attempt is made to adjust these populations. For example, one might think that while the output of retirees relative to their consumption is lower than a working age person, that output is still positive. Similarly for children. Indeed Francis and Ramey (2005), attempt to include a subset of both of these populations in their measure of the potential labor force. A generalization of the model might wish to specifically consider this aspect. 


\subsection{Key Features of the U.S. Data}

To begin, the model will be tested against data from the United States. Figure 2 shows the total population, the working age population, and the population under the age of five for the United States from 1940 to 2099 (data from 2005 forward are projections ${ }^{16}$ ). The original baby boom, the baby bust, and the subsequent baby boomlet are evident in the data. The growth rate of the population under five is high relative to the rest of our sample from 1937 to nearly $1960^{17}$. Figure 3 shows the evolution of the age 5 and under population as a percent of the total population from 1901 to 2003 . Notice, over the $20^{\text {th }}$ century the percent of the under-five population has fallen from around 12 percent in 1901 to just under 7 percent in 2003 . The dynamics of the under 5 population have direct implications for the dynamics of the working age population (i.e. a smaller under-five population in 1980 leads to fewer 25 year-olds in 2005). This impact can be seen in figure 3 .

Figure 4 shows the evolution of the working age population as a percent of the total population from 1940 through 2099. As a result of the baby boom, the working age population begins to rapidly increase around 1970 and then begins to decrease around 2020. For one remarkable 30 year episode, the working age population in the United States grew at a rate much greater than its long-term average growth rate. Over approximately the next 30 years, the working age population relative to the total population is predicted to shrink.

There are several key features of this data which the model will attempt to match. First and foremost the model will attempt to replicate real house price data from 1963 through 2005. Real house prices for the United States are shown in Figure 5. The relative price of housing has doubled over the past 45 years. Over the same 45 year period, there have also been several substantial swings in house prices. The challenge for any house price model is to match both the substantial increase over the entire period and at the same time match the intermediate fluctuations in house prices. We will show the model presented above, when fed the time path of the U.S. working age population, is capable of reproducing both features of the data.

\footnotetext{
${ }^{16}$ Demographic projections are often thought of as highly inaccurate (Porterba (2004)). However, even ex post, the evolution of the age population in the United States appears to be dominated by the baby boom. This dominance remained despite large changes in the pattern of immigration over the post war years.

${ }^{17}$ Greenwood et al. (2002) date the start of the baby boom for the United States in 1936. Indeed, by any measure one might choose - fertility rates, birth rates, population growth - the baby boom is obvious in the data and importantly the baby is not an isolated post-WWII event. Further, as this paper takes the existence of the baby boom as given and merely traces through the impact of the baby boom conditional on its occurring, we also do not dispute Greenwood et al's reason, technological progress, for the boom occurring.
} 
Second, the model will attempt to match the time series of long-term real interest rates for the United States. Real interest rates for the United States are shown in Figure 6. The solid bold line is the real ten-year Treasury rate. The dashed black line is the real one-year Treasury rate. These series are created by subtracting a measure of inflation expectations from the nominal rate. If the risk premium, that is the agent's view on the volatility of inflation are not constant, then these time series may differ significantly from the true real rate.

In particular, the data spans two relatively stable and low-inflation periods - 1950 to the late 1960s and the mid-1980s to the present - and a high and volatile inflation period - 1970 to the early 1980s. It is likely that inflation expectations are reasonably approximated and that the risk premium is fairly constant over the stable periods but for the 1970s there is no good method of determining the accuracy of the real rate. The fact that the measured real rates are quite negative does give one pause. Arguably inflation stabilized by the mid-to-early 1980s as a result of the Volcker disinflation. However, a recent paper by Goodfriend and King (2005) argues that inflation expectations remained quite high over this period. Hence, the true level of the real rate over the early 1980s is probably not well represented by my measure of real rates.

Nevertheless, I characterize the long rate as having two humps. The first hump runs from 1954 to 1977 and achieves a peak in 1966. The second hump covers the period 1978 to 2005 and peaks in 1984 . I will completely ignore short-term fluctuations in the measured real rate. The model will be compared to the two-hump shape of the real rate.

It is worth noting how consumption in the model measures up to consumption in the data. In the model, one of the most important dynamics is the increase in consumption between 1973 and 2004. Over this time period, model consumption increases 18 percent. Since the stock of housing is assumed constant in this exercise, the consumption of goods relative to consumption of housing services increases the same amount. For U.S. data between 1973 and 2004, real consumption as measured by line 1 of table Table 2.3.3. from the National Income and Product Accounts increased by 98 percent, a bit more than consumption in the model. However, the growth rate of real consumption relative to real housing services, line 14 of table 2.3.3, also rose 18 percent. Since what matters most for the model is the relative growth rate of consumption this is very close. Therefore, ignoring relative productivity changes in the model seems to be well approximated by the data at least in the very long run. This allows the model to avoid taking a stand on the pattern of productivity growth in future years. 


\subsection{Fitting the Model to the Data}

The only external input to the model is the relative size of the working age population. This data was shown in Figure 3. The baby boom has effected the relative size of the working age population since they were born. The size of the working age population declined steadily from 1945 to around 1973 . Note that this decline ended 25 years after the beginning of the baby boom implying the decline is occurring as older cohorts are retiring and the boomers are not yet of working age. Since 1973, the percentage of the population of working age has increased fairly steadily. The influx of baby boomers into the workforce moved the ratio of working age population to total population from a low of around 79 percent in 1973 to nearly 96 percent in 2005. The ratio is projected to hit an all time high of 97 percent in the year 2017. In the model, these changes in the proportion of the working age population feed directly into the time series of labor input and hence feed directly into changes in consumption.

Recalling the relative forces on house prices from the simulation and theoretical analysis sections, contemporaneous increases (falls) in consumption increase (decrease) house prices. Future, changes in consumption may put upwards or downwards pressure on consumption depending on whether the inter or intratemporal elasticity of substitution is stronger. As a result, given the increase in the working age population over the sample period, matching the general increase of house prices is straightforward.

\subsection{Matching the Average Increase and Mankiw and Weil}

To illustrate the ease with which the average trend is house prices is matched, the discount rate is set to zero leaving only the parameters $\gamma$ and $\alpha$ to match the average time series of house prices. The solid bold line in Figure 7 gives the results of this exercise. The object of the exercise is to match the average increase in house prices over the time period. This will be true if the endpoints of the simulated and actual series match. In other words, the model is to match two data points using two degrees of freedom. For convenience, set $\gamma$ such that the price series match in 1963 and then change $\alpha$ until they also match in 2005. The average increase between 1963 and 2004 is exactly replicated. In this case, the price of housing is also simply a monotone transformation of the working age population.

One note of interest is that in this example, the results of Mankiw and Weil (1988) can (essentially) be replicated. With no discounting, the interest rate changes implied by the model do not exist which brings 
the results much closer to their results. The working age population must be altered to match the years of peak housing demand from their model. Take the working age population as the population between the age of 40 and 55 as they did in their paper then use $\alpha$ to match real house prices in 1989 . The ball and chain in Figure 7 shows the results of this exercise. House prices increase until the late 1980s and then they fall around 25 percent over the next 15 years. Had real interest rates not mattered, as was shown by the regressions conducted by Mankiw and Weil, their model would have been exactly right. Of course, this method also fails to match high frequency movements in the price of housing. Apparently, both the effects of the housing demand and the discount rate are needed to replicate house prices.

\subsection{The Calibration}

Moving on to the actual calibration of the model. Three parameters from the model are adjusted to replicate the time path of house prices $-\beta, \sigma$ and $\alpha$. It turns out that a value of $\beta$ near 0.96 works very well in the calibration. This value of $\beta$ implies a risk-free rate of around 4 percent when the working age population is in a steady state, a not unreasonable number for annual data.

With $\beta$ fixed, there are three remaining parameters to calibrate, $(\sigma, \alpha, \gamma)$. The parameter $\gamma$ is chosen so that the indexes of the two series match in 1994. This year is chosen because it fits well between two turning points in the data. It is prior to the beginning of the current run-up in house prices and it is after the turndown in prices which occurred following the 1989 house price peak. The calibration proceeds as follows: First, compute the price path implied by every pair $(\sigma, \alpha)$. Given a path, check to see if the end points of the two data series coincide. If they do not, throw out the pair. Second, for each remaining price path, check the distance between the implied path in 1989 and 1979. Keep the pair with the minimum distance between the simulated data and the actual data. Essentially, we force the model to pass through the points 1963, 1994, and 2005 (we have three parameters so there is guaranteed to be at least one combination which satisfies the choices the three points). Then given that the model passes through the three points, the fit of the model is tested against the two largest peaks in the data.

There are, of course, other criteria which could have been used in order to match house prices. Fro example, a careful implementation of non-linear least squares would have achieved a fit with the minimum squared errors. However, the above method allows the model to achieve the best fit in terms of the shape of the underlying function. The challenge in house price models is in matching the turning points. The 
method outlined above turns out to do a very good job at matching these points. Statistical best fit routines tend to minimize the deviations caring very little about the overall shape. In this sense, the routine used here is just a naive shape fitting algorithm.

\section{Does the Model Fit?}

The output from the calibrated model is not fit to the data. From this point forward, no changes will be made to the parameters of the model $-(\beta=.96, \sigma=5, \alpha=-.05)$. In other words, from this point forward, the model parameters are taken to be data. In this section, house prices, interest rates, yield curves, and macroeconomic volatility implied by the model are compared to data on the relevant series.

\subsection{House Prices}

The path of house prices is given by the solid black line in Figure 8. The model matches the end points of the data and does a good job of replicating the shape of the data. In particular, at every date in which the data exhibit a peak in house prices (with the single exception of 1973), the model also delivers a peak. In other words, the model has replicated the general shape of the data.

The general upward trend of house prices over the period is primarily attributable to the trend increase in consumption driven by the increase in the working age population over the period. Recall from the section above on the key features of the U.S. data, that the relative growth rate of consumption to housing is the same in the model and in the NIPA accounts. Therefore, this impetus in the model and the U.S. data are the same.

The mechanism which is driving up the relative price of housing over time is its relative scarcity with respect to consumption of other goods. Glaeser et al (2005) attribute this scarcity to manmade scarcity driven by increasing levels of building regulation (see the excellent discussion by David Francis in the September 2005 NBER digest). This paper is fairly consistent with that hypothesis in that the restriction on the relative to growth of housing binds and creates the price increase. However, in the model housing per capita is constant over time. It just so happens that in the earlier decades, 1940 to 1960, the working age population, and hence demand for housing, was falling.

Given that the relative changes in consumption between the data and the model are similar, it is of minor 
interest to compare the intratemporal elasticity estimated by the model with previous work. Both Piazessi et al. (2005) and Davis and Martin (2005) estimate intratemporal elasticities well above 1. Their elasticity estimates are higher because they do not condition their models on the future fall in house prices. In essence, their models assume that house prices will evolve in the future according to the backwards looking statistical model. In other words, observing the same fall in interest rates and the same change in consumption without knowledge of the future fall in house prices their models predict increases in house prices which are greater than can be supported by a low elasticity of substitution. In this model, a reasonable elasticity parameter is found because the model explicitly conditions on the future fall in prices. This aspect alone keeps prices from being "too high."

The deviations in the model are caused by the interplay of contemporaneous changes to rents, the growth rate of future rents, and the future sequence of discount rates. As mentioned above, the model replicates the general shape of house prices, however, the magnitude of the swings in house prices generated by the model are not as large as those generated by the data. By design (see the calibration description above), the model comes fairly close to the peaks in 1989 and 1979. The model does not do a good job of following the downturn in prices following the 1979 peak. Indeed, the model exhibits a fairly mild downturn compared to the 20 percent fall in the data.

The model gives a gloomy view of house prices going forward. Figure 8a shows the forecast of house prices. In the near term, house prices will peak in level terms sometime between 2005 and 2010, the exact date of the peak turns out to be sensitive to the calibration (recall that all acceptable calibrations pass through the 2005 end point). Indeed the date of the collapse itself (shown in 2015 in the current calibration) can be moved as early as 2008 by decreasing $\alpha$ slightly relative to $\sigma$. Following the peak, house prices decline over 30 percent in value over the next 50 years. While this number seems quite large, it must be placed in perspective. Real house prices fell almost 20 percent in the three years following the 1979 peak. Real house prices also fell around 30 percent in the United Kingdom following their 1989 peak.

Will this decline in house prices occur? There are several channels through which the results of the model could give a misleading prediction of future prices. The first and perhaps most unlikely is that the rate of productivity growth in consumption goods picks up sufficiently relative to productivity in housing output to offset the decline in labor input. Second, and more likely, is that the model assumes that agents over the age of 65 have zero productivity. This is an unrealistic assumption. Agents over the age of 65 can 
work and if they chose to do so in mass numbers then the timing of the downturn might be quite different. I would note that they are most likely not as productive as younger workers and almost every body agrees (see Francis and Ramey) that at some point they will no longer be productive. Keep in mind, that while 30 percent seems fantastically large, I will show data for Japan in which the model exactly replicates the 34 percent fall in Japanese real house prices over 15 years.

\subsection{Interest Rates}

Figure 9 shows the time path of long-term real interest rates from the model between 1954 and 2050. The vertical line demarcates 2005. While above the increase in house prices was characterized as being attributable to the increases in rents attributable to the increase in consumption, the path for long term interest rates indicates that interest rates have also played a significant role. Real interest rates have fallen considerably over time in the model. Although most of the decline occurred over the early years of the sample.

The long rate exhibits two pronounced humps. The first and largest hump runs from 1954 to 1980 and peaks in 1965. Interest rates are very high in the 1960s because the agents in the model anticipate the increase in output implied by the baby boomers entering the workforce in the early 1970s. Interest rates fall from their early peak until they begin to increase around the mid-1980s.

The second hump in interest rates occurs between 1984 and 2017. Notice, that the 1989 house price peak occurs during a time of rising real interest rates. That is consumption increases enough over this period to offset the decline in prices which would have been implied by the rising interest rates. ${ }^{18}$ Interest rates are high early in the 1990s because consumption is temporarily low as a result of the baby boomlet in the early 1990s and because households can look forward to the rapid growth in consumption which occurs in the second half of the 90s as the relative size of the working force population reaches a sample high.

Going forward, long-term interest rates continue to decline until around 2020. The rise in interest rates following the year 2020 reflects the dying off of the baby boom generation. As that boom is slowly removed from the population figures, the economy gradually moves back to its steady state interest rate of just slightly

\footnotetext{
${ }^{18}$ In U.S. data, real rates also rise over this period. This period emphasizes why it is so difficult to use regression analysis to understand the relationship between house prices and interest rates. Regressions over this period, either in actual data or from the model, imply a negative relationship between interest rates and prices. Therefore, inclusion of this period in a study, tends to weaken the implied relationship. This is one of the reasons that Mankiw and Weil did not include interest rates in their study. The interest rate effect would have gone the wrong way.
} 
above 4 percent. Notice, that the interest rate takes a long time to revert to its steady state level. The length of time reflects the long intervals over which demographics can effect macro variables. The long-rate in this model is of course just the accumulation of short rates but it is much better at showing off the trends in the data. The discussion now turns towards an explicit discussion of the short-rate.

Figure 10 compares the interest rate from the model to the real interest rate computed from the 10 year treasury rate. The model does a good job of tracking the increase in the real rate between 1954 and 1967 and it hits the turning point when real rates begin to decline from 1967 through 1972 . The model does not match the data from 1972 through the late 1980s. However, from 1990 forward the model and the data are exactly in line. Both series record the long-term decline in real interest rates.

For the 1970s, the fact that the model does not replicate measured real rates is not surprising. This period of high and volatile inflation makes adjusting for inflation expectations over this time period difficult. Typically large negative real rates are measured and my measured real rate series is no different. Over this period, it is likely that the measured interest rate exhibits a downward bias.

However, there are some interesting aspects of the yield curve over the 1970s which correspond to the yield curve in the model. Over the mid-to-late 1970s the yield curve was consistently upward sloping. The common interpretation of this result is that agents had embodied large inflation expectations into the yield curve through the Fisher effect (Piazzesi and Schneider (2005)). In this model, the real yield curve (for bond horizons up to 30 years) is upward sloping. Short rates, in this time period, are still declining. Long rates however have begun to fully incorporate the anticipated increases in output which will occur beginning in the mid-1980s.

The model also misses interest rates in the early 1980s. In the early 1980s, measured real rates are very high. This is the period of the Volcker stabilization. Recent work by Goodfriend and King (2005) shows that survey inflation expectations in the early 1980s seem to be conditioned on the Federal Reserve's stated policy (low-inflation). Yet bond markets, the public, and the Federal Reserve ${ }^{19}$ itself placed considerable weight on a return to a high inflation environment, implying our estimate of the real rate through this period exhibits a substantial upward bias.

However, even just considering the period from 1972 to 1990 as a complete miss in terms of interest rates, the model does a remarkable job of matching the overall pattern of interest rates. Notice that the model is

\footnotetext{
${ }^{19}$ Goodfriend and King infer the expectations of the Federal Reserve from published minutes and Federal Reserve forecasts.
} 
exactly matching the evolution of the long rate for 37 of the 55 years in our sample. Most importantly the model replicates the long decline in real rates in the late 1990s. This decline is often attributed to improved monetary policy. However, I take it as supporting evidence that the retirement of the baby boomers will impact output in a substantial and negative way.

Figure 11 shows the path of the model one-year interest rate. One of the most interesting outcomes of the model is the behavior of real short-term rates in the late 1960s and 1970s. The short-term interest rate skyrockets reflecting the entry of the baby boom into the workforce. Recall from the previous figure, the first negative real rate from the data appears in 1954. Interestingly, the model also predicts a negative real rate in the years 1954 and 1957. Note that the volatility in the short-rate appears to be higher in the first two decades of the sample than in later periods. Since, in this model, the short interest rate is isomorphic to changes in output, this volatility in the sort rate maps directly into volatility in real output.

\subsection{Macroeconomic Volatility}

Output volatility drops sharply in the model in 1984. Figure 12 gives the standard deviation of the real interest rate over the period 1966 through 2004. The statistic is the ten-year backward-looking standard deviation divided by the average level of interest rates over the same period. The horizontal dashed line is to emphasize the difference in standard deviation between the first and second part of the sample. The average standard deviation prior to 1984 was around twice the level of the standard deviation post 1985. This result is strikingly similar to a series of recent results following McConnell et al (1999) which shows that there was a sharp decline in U.S. real GDP in 1984. This decline has been attributed alternatively to improved monetary policy (Clarida et al (2000)), improved business practices (McConnell et al. (1999), improved mortgage markets associated with regulation Q (Dynan et al (2005), or simply to a reduction in the volatility of macroeconomic shocks (Stock and Watson (2003)). Related to the last point, Ahmed et al. (2002) find that the reduction in volatility is likely attributable to old fashioned good luck.

In the tradition of naming ones residuals, I name this "good luck" demographics. That is, as the baby boom has aged, the economy has moderated. In the model at hand, the moderation come from the fact the by the mid1980s the baby boom was fully assimilated into the workforce and had yet to begin retiring. Therefore, the working age population stabilized implying fewer and smaller shocks to the size of the workforce. However, the demographics may play an even greater role than implied by the current 
paper. The age profile of the workforce is skewed towards workers in their prime working age. Workers in this age group are less likely to change jobs, have fewer days out from work, and tend to find a new job quicker conditional on unemployment (Shimer (2002)).

\section{International Data - A Test of the Model}

The question arises as to whether or not the fit of house prices to the model is simply one generated by coincidence. That is, because there exists only a single time series of house prices and demographics, there is a possibility that the model fits well only by chance, one of the grand coincidences in the data. In addition, while I tied my hands in the calibration using only two parameters to fit the shape of the data, perhaps I was lucky and chose the other two parameters in a way which implied a best fit. To find out the answer the question, I turn to international house price data in order to test the model "out-of-sample."

International data is well suited for an "out-of-sample" test because the existence, timing, and intensity of baby booms varies across countries. For example, Japan, losing the war, did not have a post-WWII baby boom. The United Kingdom on the other hand had fairly low fertility during the war, perhaps the Battle of Britain impacted fertility rates, but had a sharp baby boom immediately following the war. Therefore, the demographic impulses in these countries are going to be very different from the demographic impulses in the United States.

In addition, turning to international data gives a feel for the power of the demographic explanation versus other explanations of house prices. For example, Glaeser et al (2005) make a convincing case that increasing land use regulations in the United States have played a significant role in the rising profile of U.S. house prices. In both Great Britain and Japan, land use regulations have been in place for a very long time (since the late 17th century in the case of Great Britain). Also, both of these countries are constrained geographically, they are both small islands. Alternatively, improved mortgage finance is also often pointed to as a proximate cause for house prices movements. Again, the timing and implementation for these improvements is varied internationally. Therefore, the demographic model's ability to price housing across these countries, all the while keeping the parameters as calibrated for the United States, is in my mind convincing evidence in its favor. 


\subsection{Japan}

Japan makes an excellent test case for the model. Japanese real house prices rose almost 40 percent between 1986 and 1990. After the 1990 peak, real house prices have fallen around 34 percent, nominal house prices have fallen even further. ${ }^{20}$ Japan is widely thought to have experienced an asset price bubble in the late 1980s, with a primary affected asset class being real estate (see for example Bayoumi and Collyns (2000), Ahearne et al. (2002), and Charkaborty (2005)). These papers give many reasons why the bubble occurred and subsequently collapsed mainly associated, in one form or another, with imperfections in the banking system. Hayashi and Prescott (2005) dispute the finding that a breakdown in the financial system caused the decade long stagnation. Instead they attribute the decline to a decade long slowdown in total productivity growth.

Demographics, if not the only driver, appears to have played a significant role in the run-up in house prices in Japan in the 1980s and appears linked to the decline in house prices over the 1990s. Figure 13 shows the time path of real house prices (dashed black line) and the data output by the model (the bold solid line). The model is capable of replicating both the 1974 peak in real house prices and the 1990 peak, albeit the model predicts the peak to occur in 1992 rather than 1990. The model, surprisingly, also predicts the fall in house prices over the last fifteen years. From the model peak year, the model predicts a 30 percent decline in house prices over fifteen years, remarkably close to the actual fall.

\subsection{The United Kingdom}

Real house prices in the United Kingdom are thought to be more volatile than real house price in the United States. Figure 14 shows that not only is this true but that the peaks in real house prices are very close to the peaks in U.S. house prices (the 1979 peak is slightly delayed). Many reasons have been given for the differences (e.g. the relative urbanization of the United Kingdom, stricter land use regulations ect.); however, once again, demographics appear to be playing a role. Figure 15 shows births in the United Kingdom versus the population under age five for the United States from 1938 through 1960 (essentially the baby boom years for the United States) ${ }^{21}$. Note the sharpness of the baby boom in the United Kingdom relative to that in

\footnotetext{
${ }^{20}$ Japan has experienced a prolonged period of deflation. The GDP deflator for Japan is nearly 14 percent below its 1990 level.

${ }^{21}$ The data, while not exactly comparable, is quite similar in nature to the fertility data presented by Greenwood et. al. (2002) figures 6 and 8. These figures show a protracted hump in fertility rates in the United States and a sharp spike in fertility in the United Kingdom.
} 
the United States. The peak of the baby boom occurs right after the end of WWII, matching the common intuition that baby booms occur right after wars, and then drops off sharply not recovering, in levels, until the mid 1960s when they have a second, though smaller in per capita terms, baby boom.

Figure 16 shows real house prices in the United Kingdom versus data from the simulated model. The model when faced with the sharp demographic changes from the United Kingdom spits out house prices with substantially more volatility than is observed in the U.S. data. The 1979 house price episode is not matched by the model and the 1973 peak is predicted two years early; however, with those two modest exceptions the model does very well at matching prices in the United Kingdom.

The predictions for prices going forward differ somewhat between the United States and the United Kingdom. Because the United Kingdom had a second substantial boom in the mid-1960s price appreciation is predicted to slow in the near-term but not actually turn negative until around the year 2010. The turndown in 2005 in the house price data does not on the surface appear to be matched by the model. However, notice that the model predicts a short-lived turn-down in house prices in 2003. A different calibration of the model would likely move this event. For example, in calibrating the model for the United States, the final peak in house prices is predicted to occur anytime between 2005 and 2010 depending on the level of intertemporal substitution and the time discount rate. Therefore, the possibility that the current turn-down is associated with either the final model peak or the short-lived pause in the model can not be ruled out.

\subsection{Ireland}

The model is applied to Ireland. I wanted to end with Ireland because it is a country without a dire prediction for house prices going forward because Ireland has a very young population. One result of the very young population is that the model does not predict a decline in house prices until the year 2033. Figure 17 shows real house prices and simulated house prices from the model. Among the countries examined in this paper, Ireland has the smoothest predicted price of housing. The model comes close to predicting the stagnant housing market between 1970 and 1994 and is able to make the turn to high house price growth from 1994 forward. The model exactly matches house prices from 2002 to 2005 . The model's predictions for house prices between now and 2010 are remarkable. Over this time period, the model predicts a further doubling of house prices.

The model predicts such different house price growth in Ireland because the Irish baby boom was quite 
different from the other countries. Irish population data is available beginning in 1950. Inferring from the growth rate of the 20 to 24 year old population, the original "post-war" baby boom in Ireland occurred quite late. The birth rate may have begun to pick-up in 1940 but did not substantially peak until 1960. More importantly for our result is that Ireland had a baby boom quite recently in the very late 1970s. This cohort enters the workforce around 1994 implying that most of the current run-up in house prices in Ireland is a result of increased output as the labor supply increases. (Note, this is also the reason the model predicts a slight decline in house prices earlier.) That same cohort does not begin to retire until around 2033. But for Ireland, even in 2033, the case for house prices is not so dire. This results from the fact that Ireland is currently in the middle of a sizable baby boomlet (the boomlet causes the change in slope of prices around 2000). This second cohort does not enter the labor force until between 2025 and 2030, somewhat cushioning the falling prices later. This cohort retires around 2065 to 2070.

\section{Conclusion}

This paper has shown that a simple model which takes as given the demographic time series for the United States is capable of replicating many of the features of U.S. post-war data. I have shown that the demographic impulse implied by the baby boom is a likely driver of both interest rates and house prices and that both of these prices are likely to be influenced for some time to come as the baby boomers slowly retire and eventually die off.

The most important idea to take away from this paper is that while many factors may affect the price of housing - changes in ability to build (Glaeser et al. (2005)), tax changes (Gervais (2002)), improvements in financial markets (Lamont and Stein (1999)), or changes to monetary policy (Ahearne et al. (2005)) - if these factors are to explain the post-war house price experience, the price movements implied by the factor must be correlated with the timing of the impulses implied by the demographic model. I do not, however, mean to imply that these other forces are unimportant.

For example, Glaeser et al. offer a political economy rationale for the increasing level of building regulation observed in the United States. They argue that as home owners become a powerful political bloc they enact regulations intended to protect the value of their investment. But who is this politically powerful cohort? the baby boomers. If it is the baby boomers, then it is also not surprising that the timing of the regulations 
correspond to the price impulse implied by the baby boom.

\section{References}

[1] Abel, Andrew. (2001), "Will Bequests Attenuate the Predicted Meltdown in Stock Prices when Baby Boomers Retire," Review of Economics and Statistics, 83(4), 589-595.

[2] Abel, Andrew. (2003), "The Effects of a Baby Boom on Stock Prices and Capital Accumulation in the Presence of Social Security," Econometrica, 71, 551-578.

[3] Ahmed, Shaghil, Andrew Levin, and Beth Anne Wilson. (2002), "Recent U.S. Macroeconomic Stability: Good Policies, Good Practices, or Good Luck?," International Finance Division Working Paper, 730.

[4] Alan Ahearne, Joseph Gagnon, Jane Haltmaier, and Steve Kamin with Christopher Erceg, Jon Faust, Luca Guerrieri, Carter Hemphill, Linda Kole, Jennifer Roush, John Rogers, Nathan Sheets, and Jonathan Wright. (2002), "Preventing Deflation: Lessons from Japan's Experience in the 1990s," International Finance Discussion Paper 729.

[5] Bayoumi, Tamim, and Charles Collyns eds. (2000), Post-Bubble Blues: How Japan Responded to Asset Price Collapse. International Monetary Fund, Washington D.C., Federal Reserve Board.

[6] Browning, Martin, and Annamaria Lussardi. (1996), "Household Saving: Micro Theories and Micro Facts," FINISH THIS CITE

[7] Ang, Andrew, and Angela Maddaloni. (2003). "Do Demographic Changes Affect Risk Premiums? Evidence from International Data," NBER Working Paper 9677.

[8] Benhabib, Jess, Richard Rogerson, and Randall Wright. (1991), "Homework in Macroeconomics: Household Production and Aggregate Fluctuations," Journal of Political Economy, 99(6), 1166-1187.

[9] Brooks, Robin J. (2002), "Asset Market Effects of the Baby-Boom and Social Security Reform," American Economic Review, 92, 402-406.

[10] Campbell, Jeffery, and Zvi Hercowitz. (2004), "The Role of Collateralized Debt in Macro Stabilization," Chicago Federal Reserve, Working Paper.

[11] Campbell, Sean. (2004), "Macroeconomic Volatility, Predictability and Uncertainty in the Great Moderation: Evidence From the Survey of Professional Forecasters," FEDS, 2004-52.

[12] Campbell, Sean, Morris Davis, Joshua Gallin, and Robert F. Martin. (2005), "The Equity Premium for Housing," Working paper.

[13] Chakraborty, Suparna. (2005), "Accounting for the 'Lost Decade' in Japan," mimeo, Department of Economics, University of Minnesota.

[14] Clarida, Richard, Jordi Gali, and Mark Gertler. (2000), "Monetary Policy Rules and Macroeconomic Stability: Evidence and Some Theory," The Quarterly Journal of Economics.

[15] Davidoff, Thomas. (2005), "Labor Income, Housing Prices, and Homeownership," forthcoming Journal of Urban Economics.

[16] De Nardi, Mariacristina, Selahattin İmrohoroglŭ , and Thomas Sargent. (1999), "Projected U.S. Demographics and Social Security," mimeo Federal Reserve Bank of Chicago. 
[17] Dai, Qiang, and Thomas Philippon. (2005), "Fiscal Policy and the Term Structure of Interest Rates," National Bureau of Economic Research Working Paper 11574.

[18] Davis, Morris, and Jonathan Heathcote. (2005), "Housing and the Business Cycle," International Economic Review 46(3), 751-784.

[19] Davis, Morris, and Jonathan Heathcote. (2005b), "The Price and Quantity of Residential Land in the United States," Working paper.

[20] Davis, Morris, Robert F. Martin, and Peter Rupert. (2005), "The Home Sector," working paper.

[21] Davis, Morris, Andreas Lehnert, and Robert F. Martin. (2005), "The Rent-Price Ratio from 1960 to 2005," International Finance Discussion Paper.

[22] D'Amico, Stefania, Don Kim, and Min Wei. (2005), "No Arbitrage Term Structure Model of TIPS," mimeo Federal Reserve Board.

[23] Dynan, Karen E., Douglas W. Elmendorf, and Daniel E. Sichel. (2005), "Can Financial Innovation Help to Explain the Reduced Volatility of Economic Activity?" FEDS.

[24] Francis, Neville, and Valerie A. Ramey. (2005), "A Century of Work and Leisure," working paper UCSD.

[25] Francis, David R. (2005), "Manmade Scarcity Drives Up Housing Prices," The NBER Digest, September 2005.

[26] Genakoplos, John, Michael Magill, and Martin Quinzii. (2004), "Demography and the Long-Run Predictability of the Stock Market," Brookings Papers on Economic Activity.

[27] Gervais, Martin. (2002), "Housing Taxation and Capital Accumulation," Journal of Monetary Economics, 49(7), 1461-1489.

[28] Glaeser, Edward L., Joseph Gyourko, and Raven Saks. (2005), "Why Have Housing Prices Gone Up?," National Bureau of Economic Research Working Paper 11129.

[29] Goodfriend, Marvin, and Robert King. (2005), "The Incredible Volcker Disinflation," National Bureau of Economic Research Working Paper 11562.

[30] Greenwood, Jeremy, Anath Seshadri, and Guillaume Vandenbroucke. (2005), "The Baby Boom and Baby Bust," American Economic Review 95(1), 183-207

[31] Greenwood, Jeremy, Anath Seshadri, and Mehmet Yorukoglu. (2005), "Engines of Liberation," Review of Economic Studies, 72, 109-133.

[32] Greenwood, Jeremy, Anath Seshadri, and Mehmet Yorukoglu. (2002), "The U.S. Demographic Transition," American Economic Review (Papers and Proceedings), 92(2), 153-159

[33] Hayashi, Fumio, and Edward C. Prescott. (2000), "The 1990s in Japan: A Lost Decade," Minneapolis Federal Reserve Working Paper 607.

[34] Helliwell, John. (2004), "Demographic Changes and International Factor Mobility," Federal Reserve Bank of Kansas City

[35] Henriksen, Espen, and Chris Telmer. (2004), "Demographic Variation, Capital Accumulation and Asset Prices," GDIA Working Papers, 2004-E26. (paper may not exist need to check) 
[36] Lamont, Owen, and Jeremy Stein. (1999), "Leverage and House-Price Dynamics in U.S. Cities," RAND Journal of Economics, 30(3), 498-514.

[37] Lim, Kyung-Mook, and David N. Weil. (2003), "The Baby Boom and the Stock Market Boom," Scandinavian Journal of Economics 105(3), 359-379.

[38] Mankiw, N. Gregory, and David N. Weil. (1988), "The Baby Boom, the Baby Bust, and the Housing Market," National Bureau of Economic Research, Working Paper No. 2794.

[39] Mankiw, N. Gregory, and David N. Weil. (1992), "The Baby Boom, the Baby Bust, and the Housing Market: A Reply to Our Critics," Regional Science and Urban Economics, 21, 573-579.

[40] McConnell, Margaret M., Patricia C. Mosser, and Gabriel Perz Quiros. (2000), "A Decomposition of the Increased Stability of GDP Growth," Current Issues, Federal Reserve Bank of New York, Vol 5(13).

[41] Meen, Geoffrey. (1990), "The Removal of Mortgage Market Constraints and the Implications for Econometric Modelling of UK House Prices," Oxford Bulletin of Economics and Statistics, 52(1), 1-23.

[42] Porterba, James. (1991), "House Price Dynamics: The Role of Tax Policy and Demography," Brookings Papers on Economic Activity, 2, 143-2.

[43] Porterba, James. (2004), "The Impact of Population Aging on Financial Markets," National Bureau of Economic Research, Working Paper 10851.

[44] Ríos-Rull, José-Victor. (1993), "Working in the Market, Working at Home, and the Acquisition of Skills: A General-Equilibrium Framework," American Economic Review, 83(4), 89-907.

[45] Ríos-Rull, José-Victor. (2001), "Population Changes and Capital Accumulation: The Aging of the Baby Boom," mimeo, University of Pennsylvania.

[46] Storesletten, Kjetil. (2003), "Sustaining Fiscal Policy Through Immigration," Journal of Political Economy, 108(2), 300-323.

[47] Yoo, Peter S. (1994), "Age Distributions and Returns to Financial Assets," Federal Reserve Bank of St. Louis Working Paper 94-002B.

\section{Data}

For the United States, I use annual data from the Bureau of the Census on the age structure of the population from 1940 through 2005. The Census department conducts a comprehensive population survey every ten years and interpolates annual figures using data on births, deaths, and immigration. For each year, the census publishes data on the resident population by five year groupings (e.g. 20-25 year olds). In addition, the Bureau of the Census publishes population projections annually and by the same age groupings through 2099. I note that, while the projections have almost always proved to be mildly inaccurate I take them as data for the present purpose. As we define the working age population as the entire population between 25 and 64 years of age, this data is taken directly from the Census.

House price data from 1970 through 2005 is taken from the OFHEO house price index. OFHEO produces a quarterly repeat sales index of house prices in the United States. While the OFHEO suffers many shortcomings (see Gallin (2005) for an exposition on this topic), it is widely regarded as the benchmark house price series for the United States. From 1963 to 1969, I use an index from the Bureau of Census for the median price of new home sales. While the OFHEO index and the data from the Bureau of the Census 
do not perfectly coincide, in growth rates, from 1970 forward, the correlation between the two series is high enough to warrant its use in order to extend the sample backwards almost an additional decade (see Davis et al. 2005). A real house price series is created using the consumer price index.

Real interest rates are computed from 1954 to 2005. Real interest rates are computed using the nominal return on the 1 and 10 year treasury bill and then deflating by inflation expectations. For the period 1954 to 1982, inflation expectations for 10 year treasuries are modeled as a five-year backwards-looking moving average of inflation. Inflation expectations for one-year treasuries are modeled as contemporaneous 12month inflation. From 1982 to 2005, inflation expectations are take from the Philadelphia Federal Reserve Boards survey of professional forecasters, available from their real-time database. I deflate the 10 year T-bill using ten-year inflation expectations and the 1 year T-bill using two-year inflation expectations. Inflation indexed bonds were traded for a large portion of my time sample. I choose not to infer real rates from these bonds as the liquidity premium inherent in these bonds is not well understood and is thought to have dropped considerably between 1989 and 1995 (see D'amico et al. (2005)).

Real house price data for Japan are from the OECD and are available from 1970 through 2005 . For demographic data, we have two choices. National data for the total population are available annually from 1950 through 2005. Deriving my definition of the working age population is not possible from this source. The Japanese data define the working age to lie between 15 and 65 years of age. 15 years is too young to be enter into the productive population. I transform the Japanese data in an attempt to remove the 15 to 24 year olds from their working age data. I use United Nations population data for this exercise

The United Nations publishes population estimates by five year age groupings similar to the U.S. data. Unfortunately, this data is only available at five year intervals (i.e. 1950, 1955, 1960 ect.). Adjusting the Japanese data is fairly straight forward. The key adjustment is moving the leading edge of their baby boom so that they enter the work force in the correct year. That is, according to the Japanese National data, a person born in 1950 would enter the productive population in 1965. I simply take this person out of the working age population until he enters the workforce in 1975 at age 25. Because the U.N. data is at a low frequency, I linearly interpolate to infer annual population adjustments. The method is coarse but comes close to the data I need.

Population projections for Japan are also take from the United Nations data. The projections are available every five years from 2005 through 2050. The data are linearly interpolated to estimate the annual data.

House price data for the United Kingdom is from the Office of the Deputy Prime Minister. This index is used instead of private indices such as Halifax or Nationwide because the data goes back farther (1969) and because the timeliness of the data is not important to the exercise at hand. Real house prices are calculated using the personal income deflator from the National Income and Product Accounts Population data is procured from (GET SOURCE). Similar to the Japanese case the data on the working age population is defined as the population between the ages of 15 and 65 . I adjust these data using the U.N. population data exactly as in the case of Japan.

House price data for Ireland are from the Office of National Statistics. Real house prices are calculated using the Harmonized Index of Consumer Prices. Irish population data is available at the same frequency and age categories as are available in the United States. No adjustments are made to the data. 
Figure 1. Real House Prices: $\mathbf{3 0}$ percent consumption fall at date $\mathbf{5 0}$ (announced at date 1)

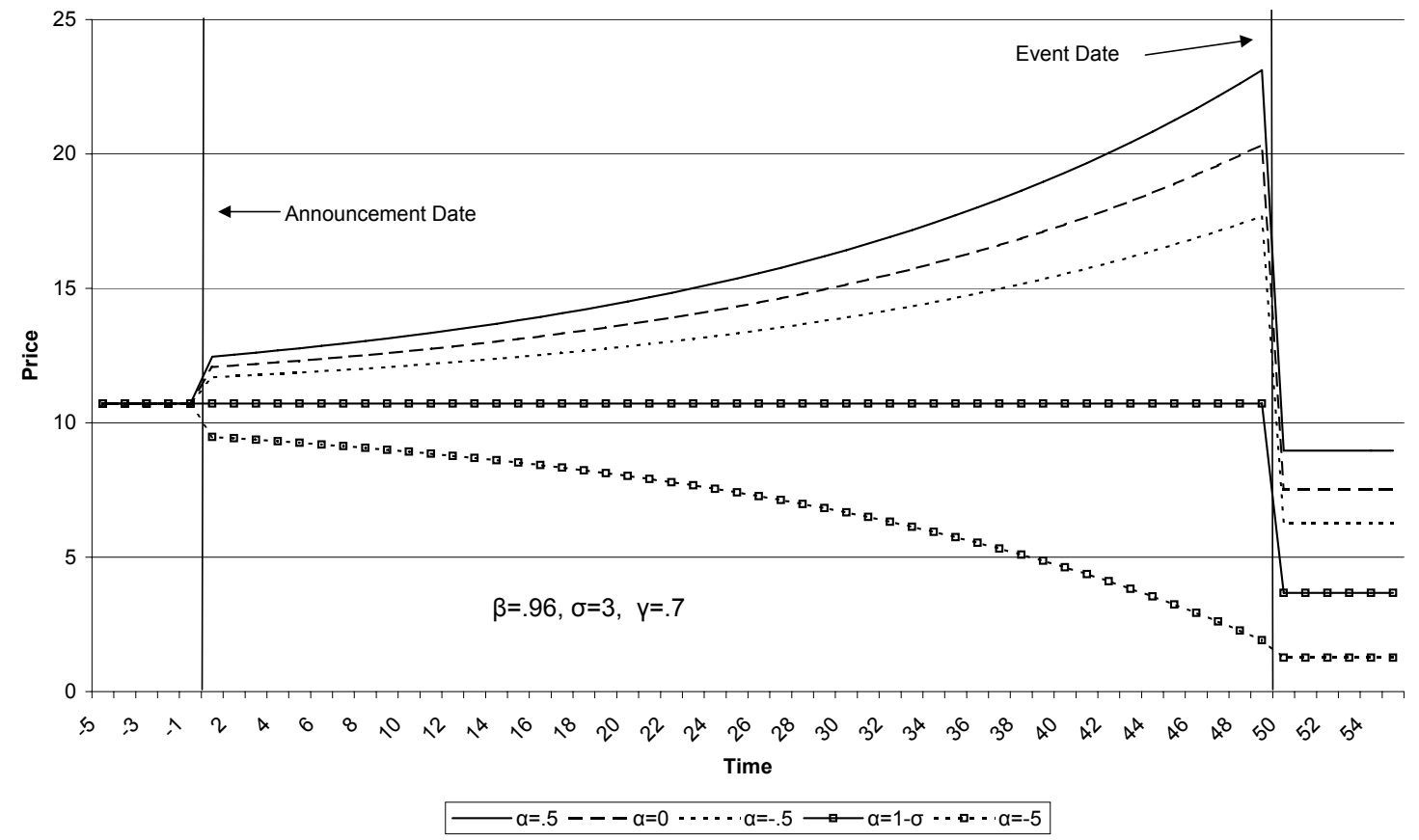

Figure 1a. Rents and Prices

Index $50=100$ $\sigma=3, \alpha=-.05$

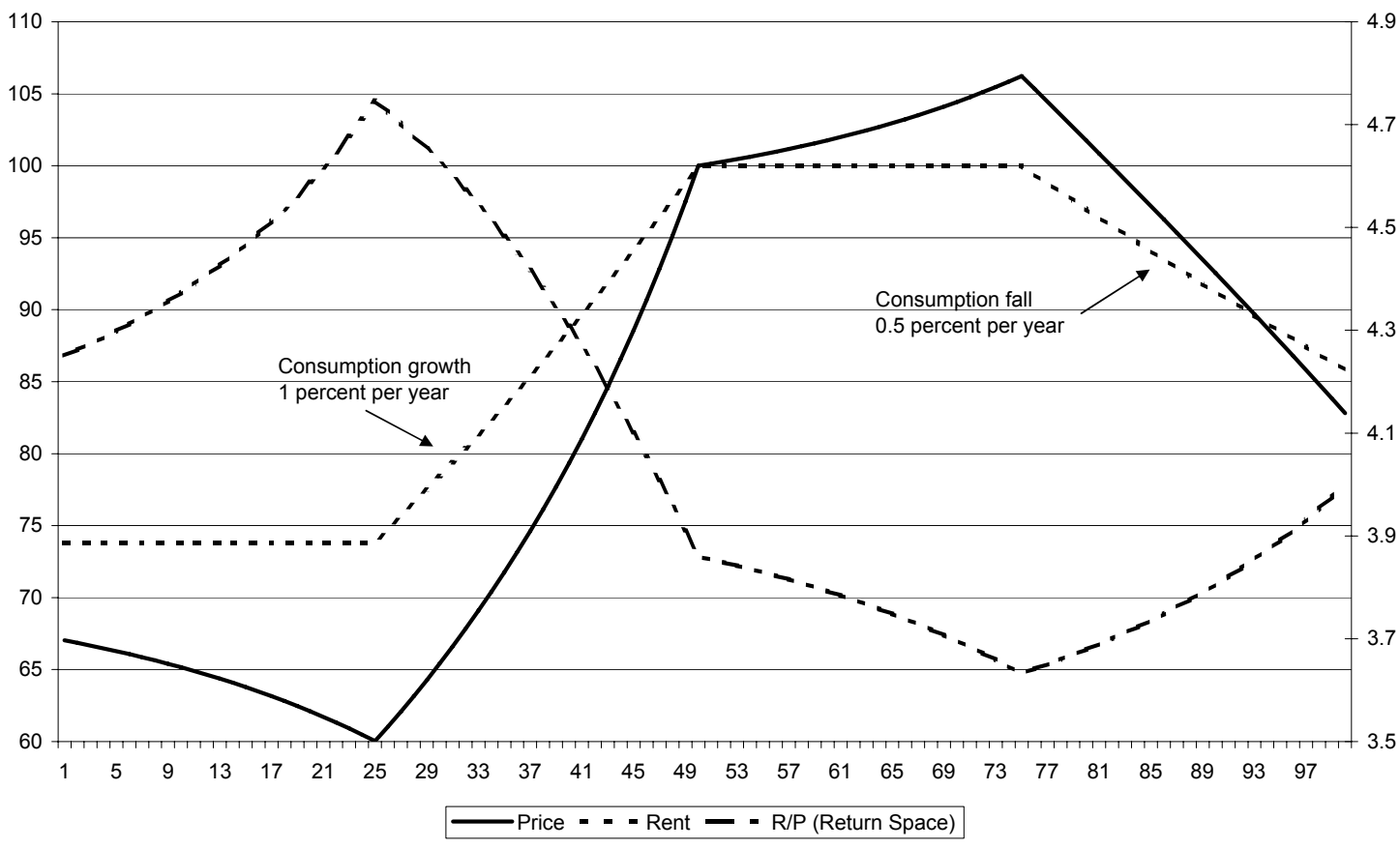


Figure 2: US Demographics with Projections Population in Thousands

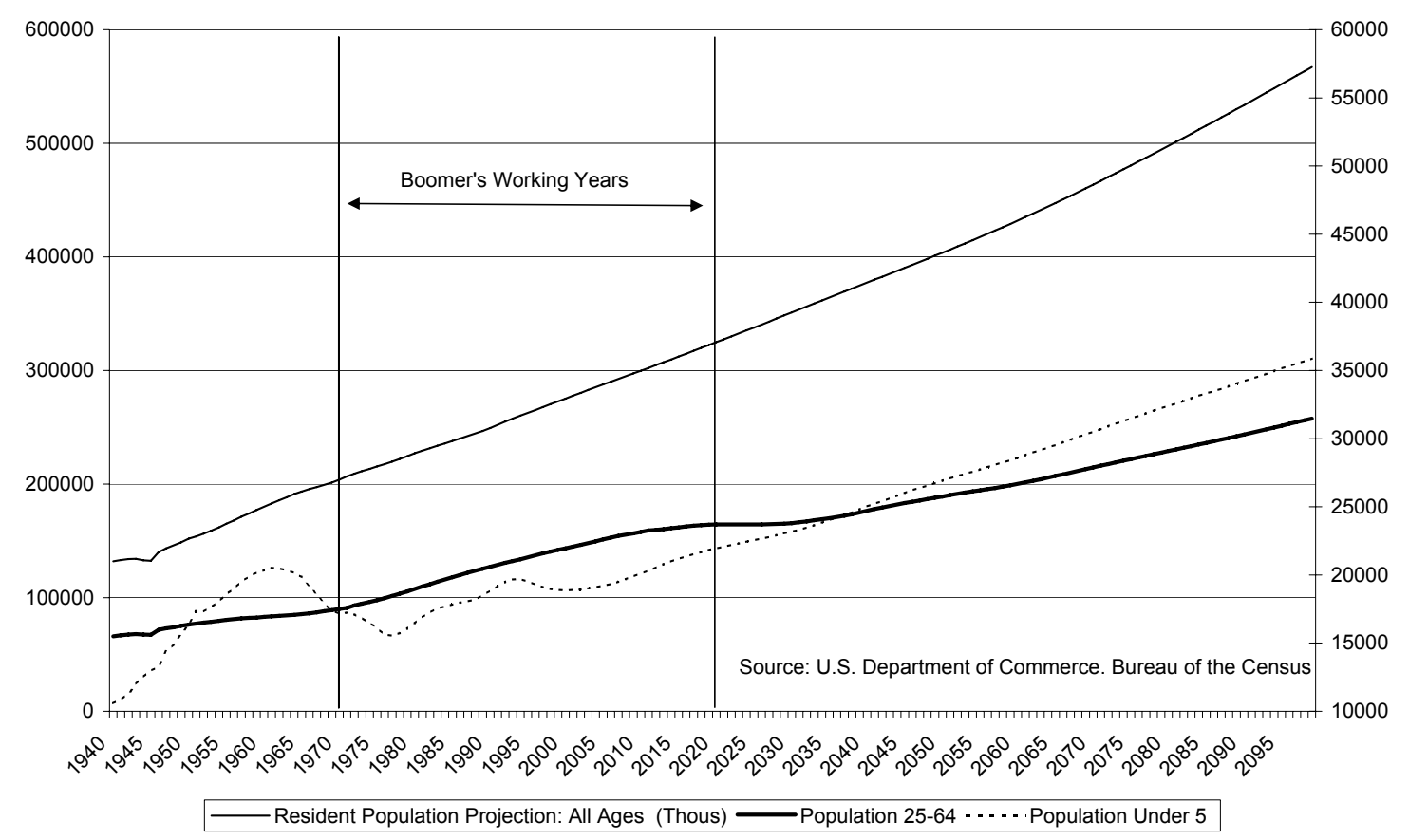

Figure 3. United States: Percent of Population Under Age 5

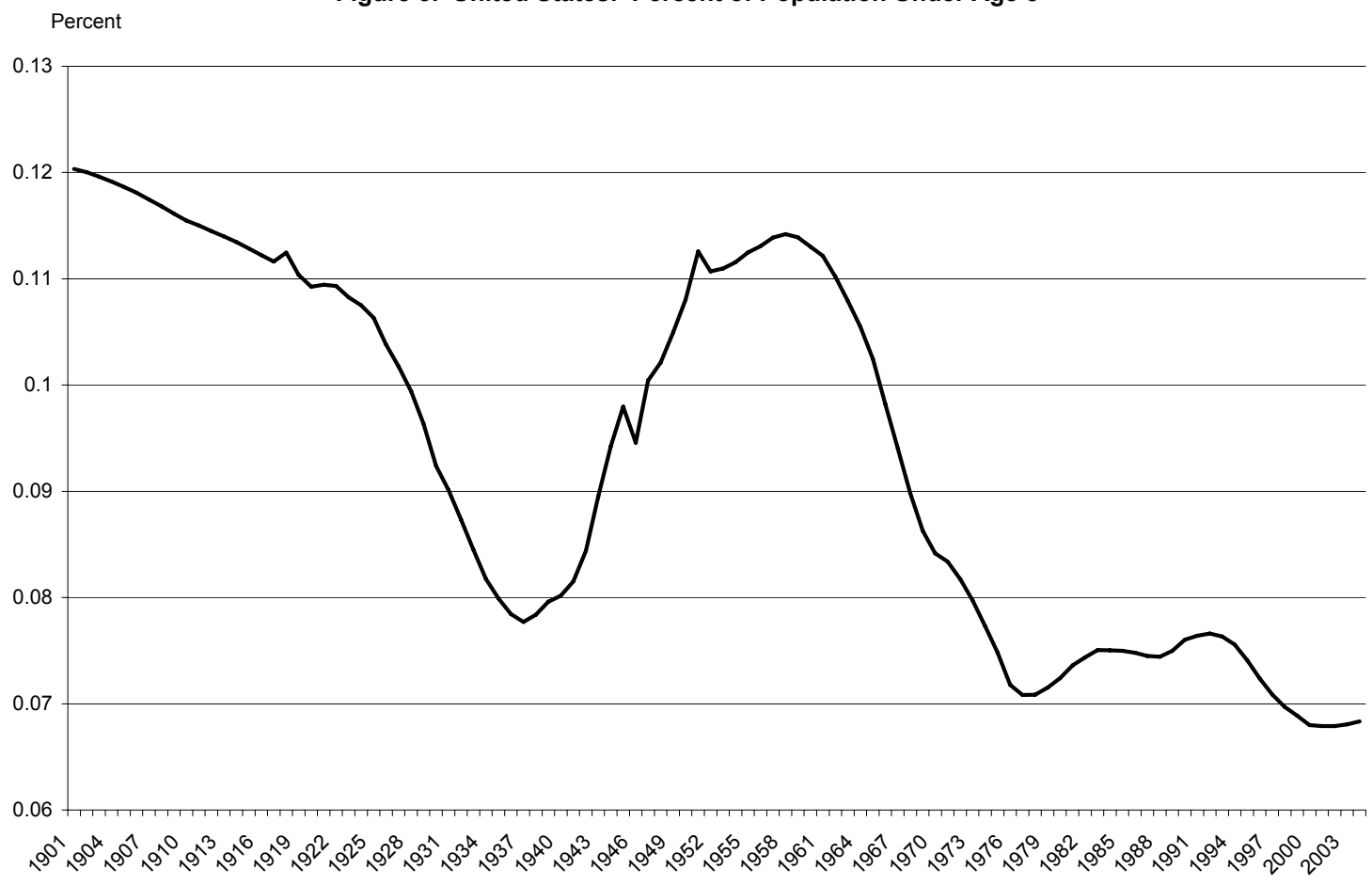

39 
Figure 4. United States: Percent of Population Working Age

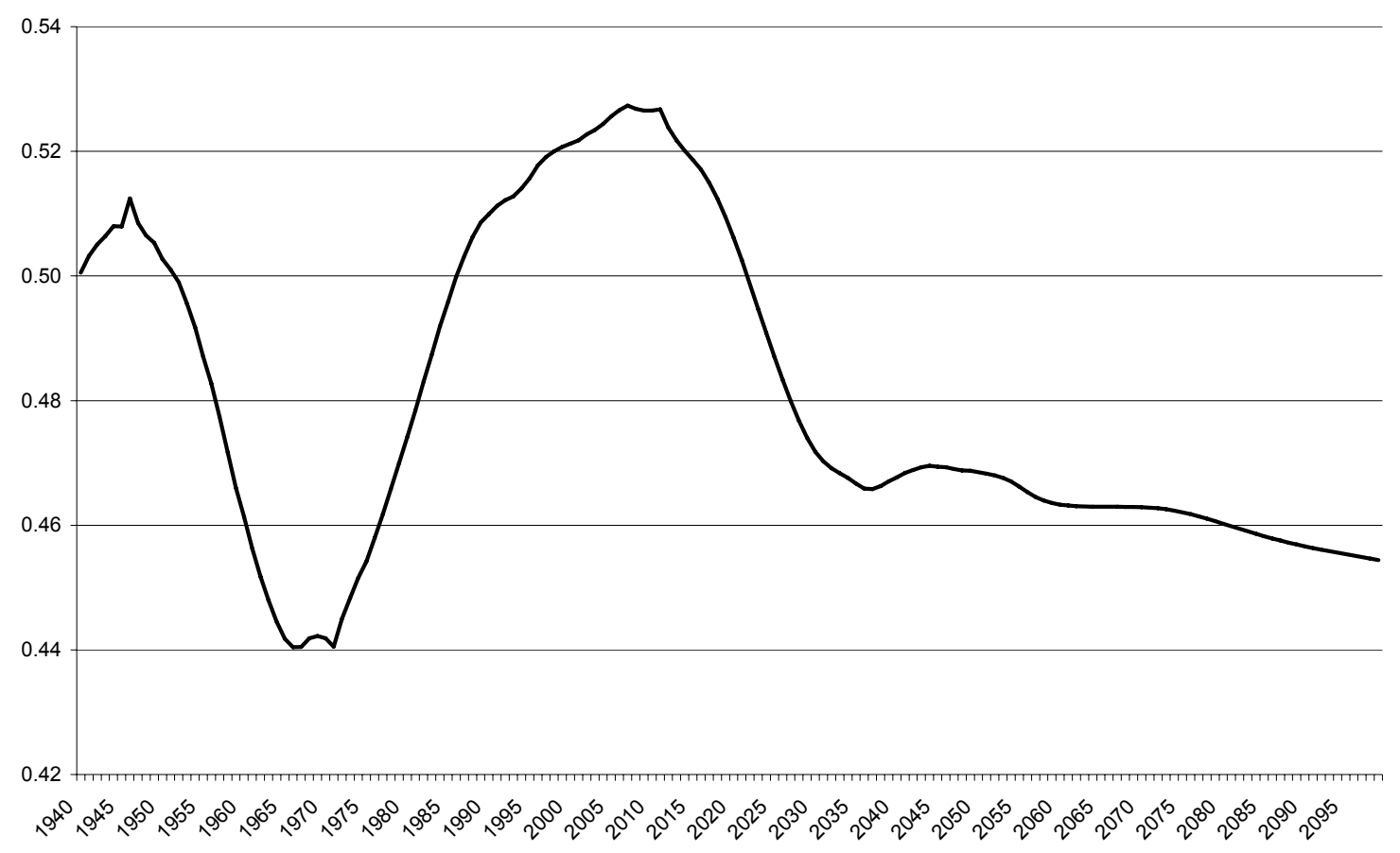

Figure 5. United States: Real House Prices

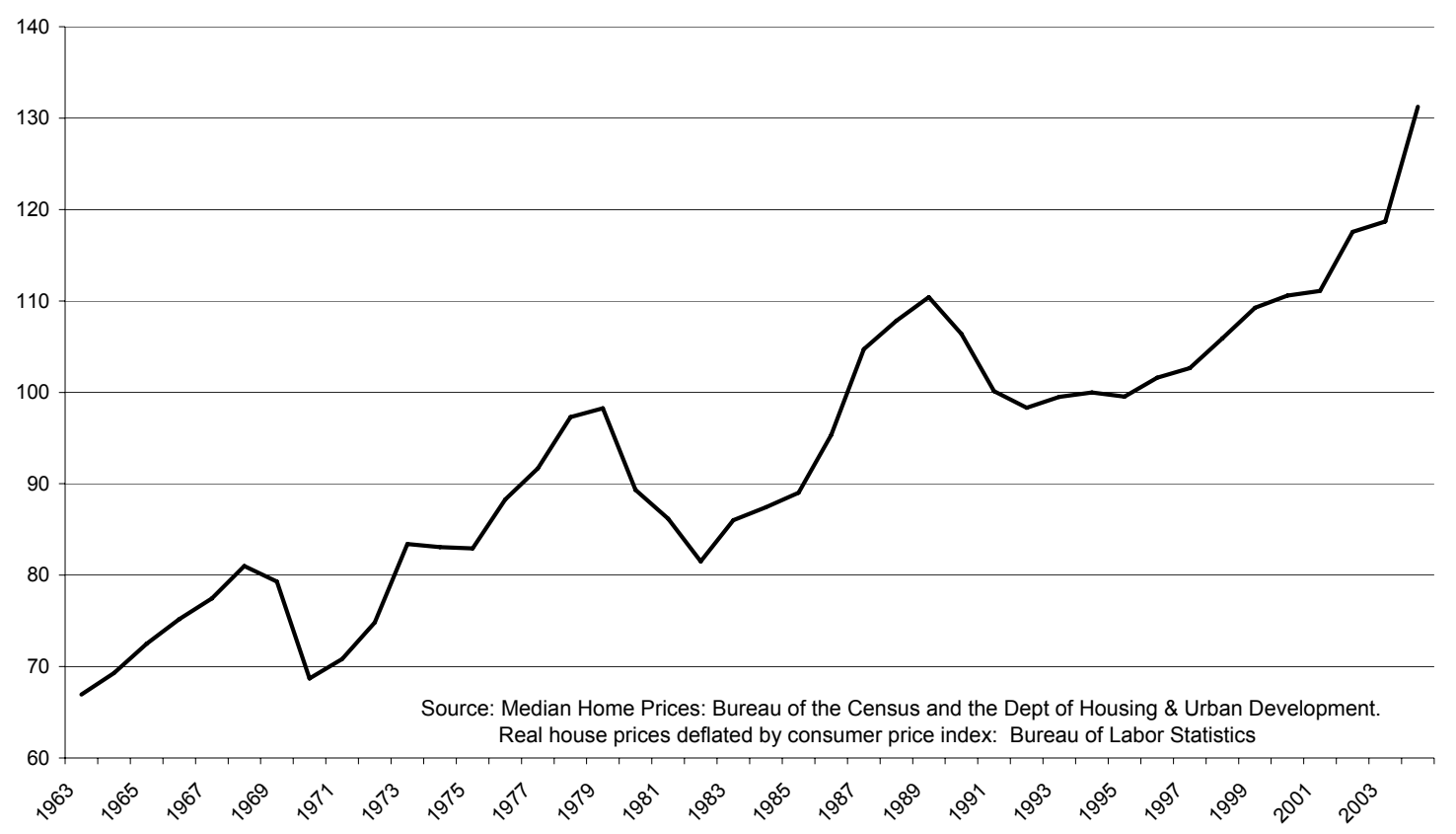

40 
Figure 6. Real Long and Short Interest Rates

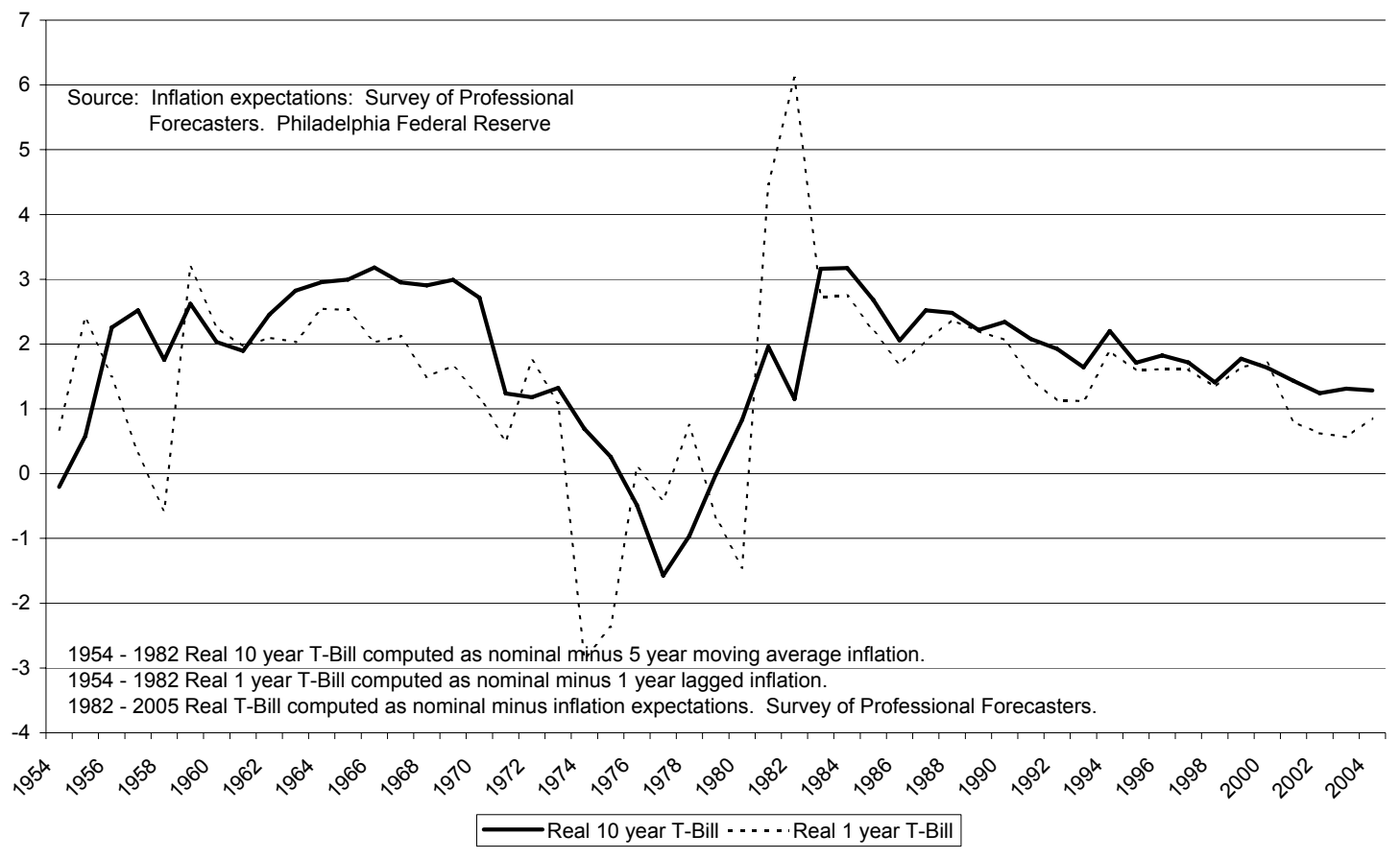

Figure 7. Real House Prices and Model House Prices

(No Discounting)

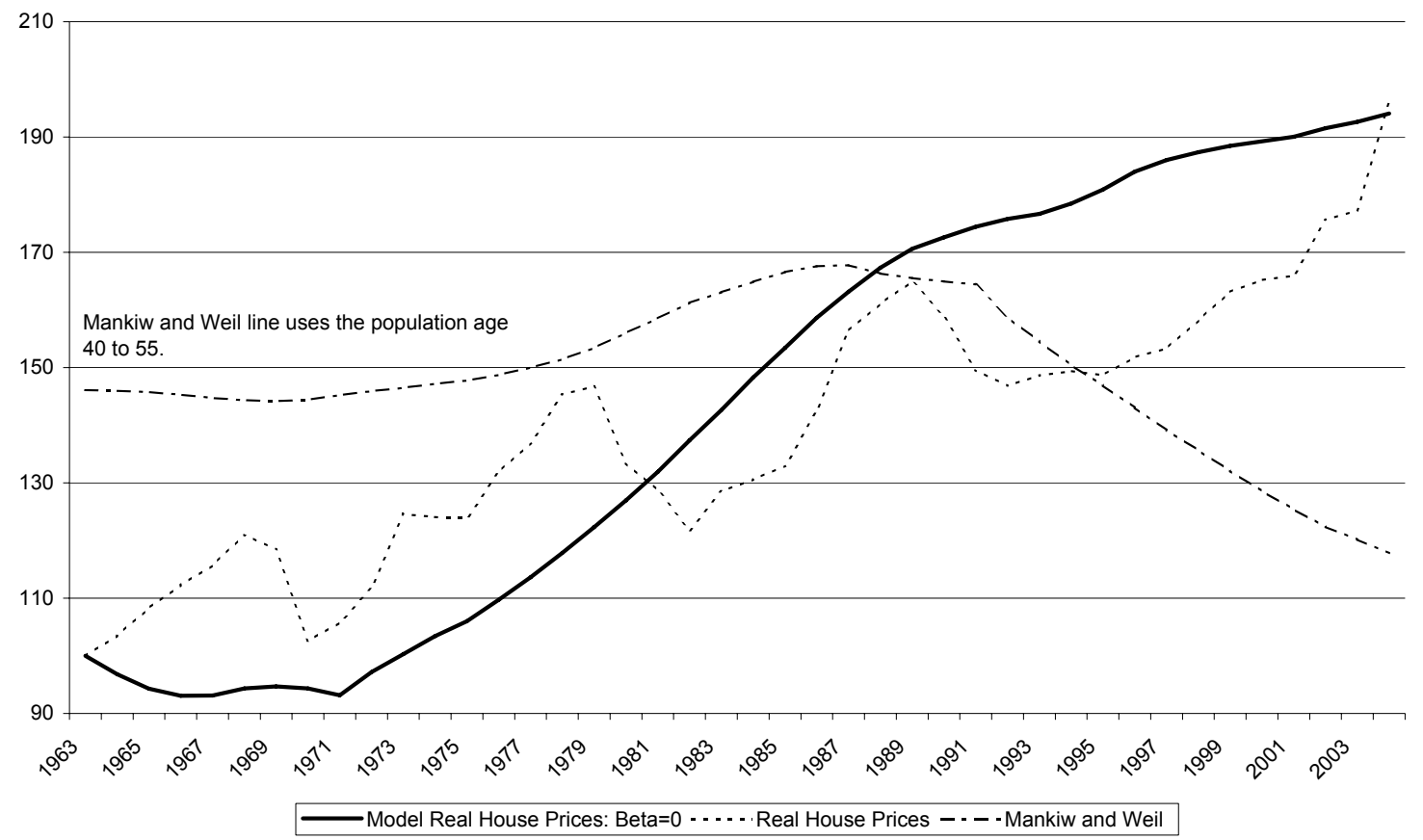


Figure 8. United States: Simulated House Prices

Index $1994=100$

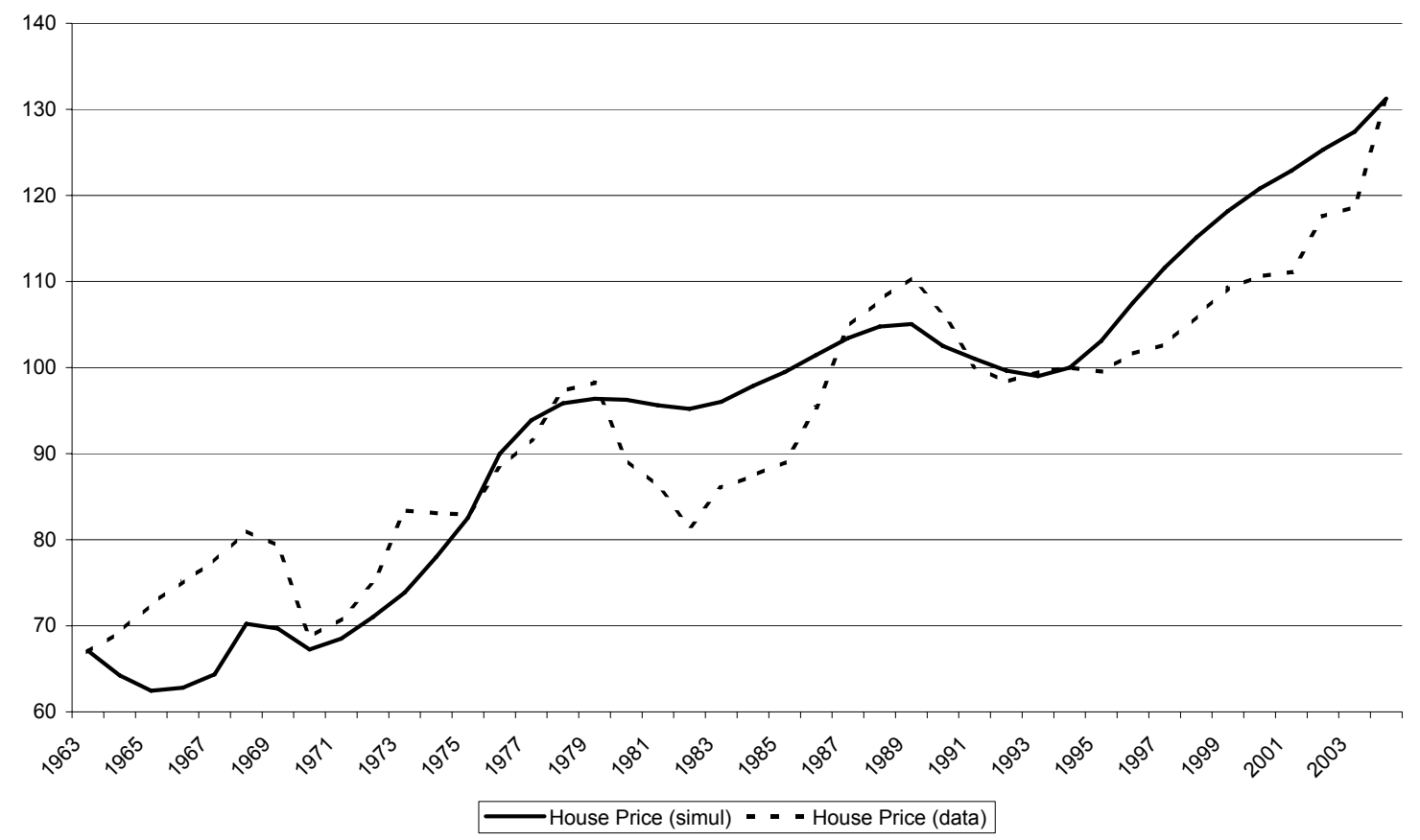

Figure Ba. United States: Simulated House Prices

Index $1994=100$

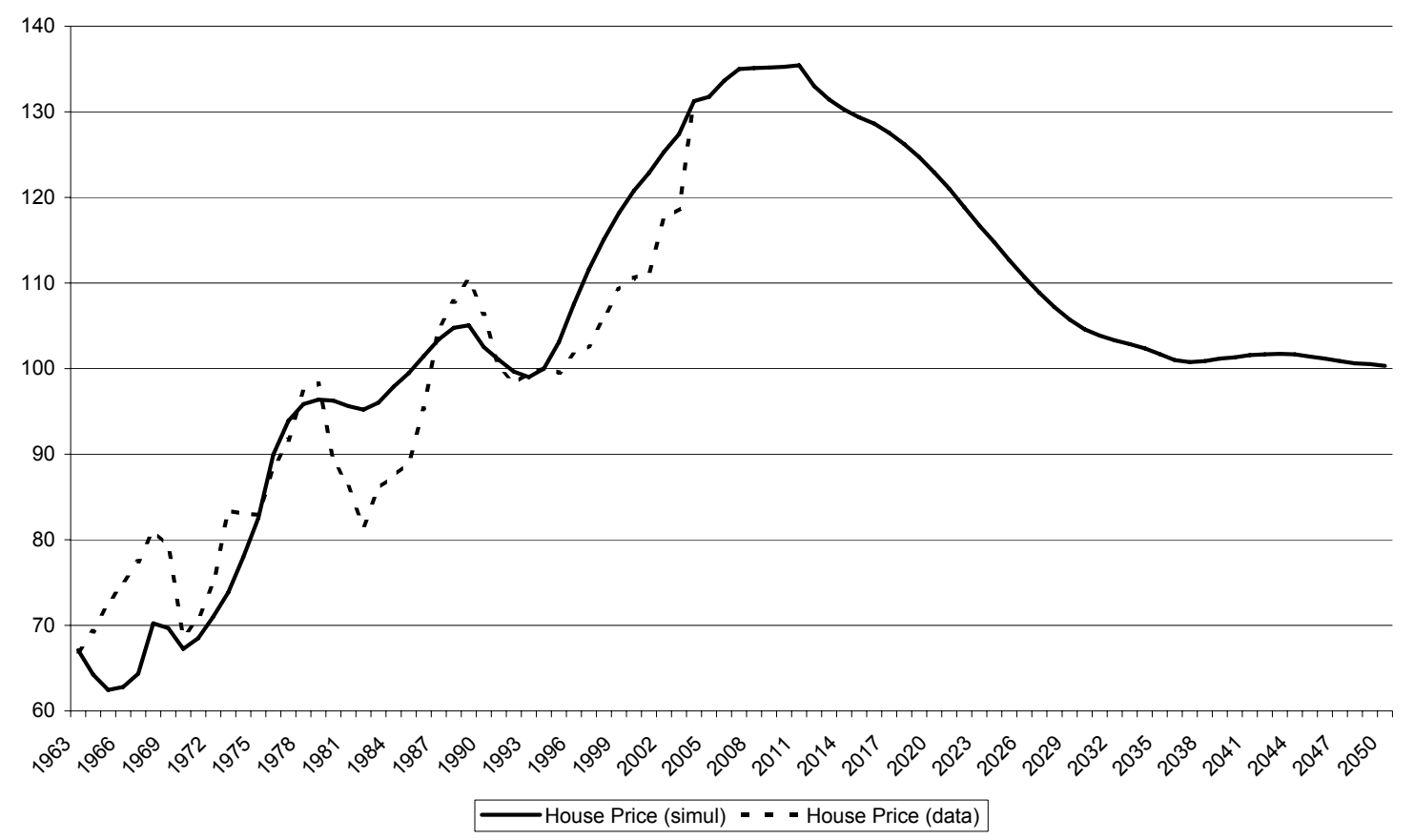

42 
Figure 9. Long-Term Real Interest Rate

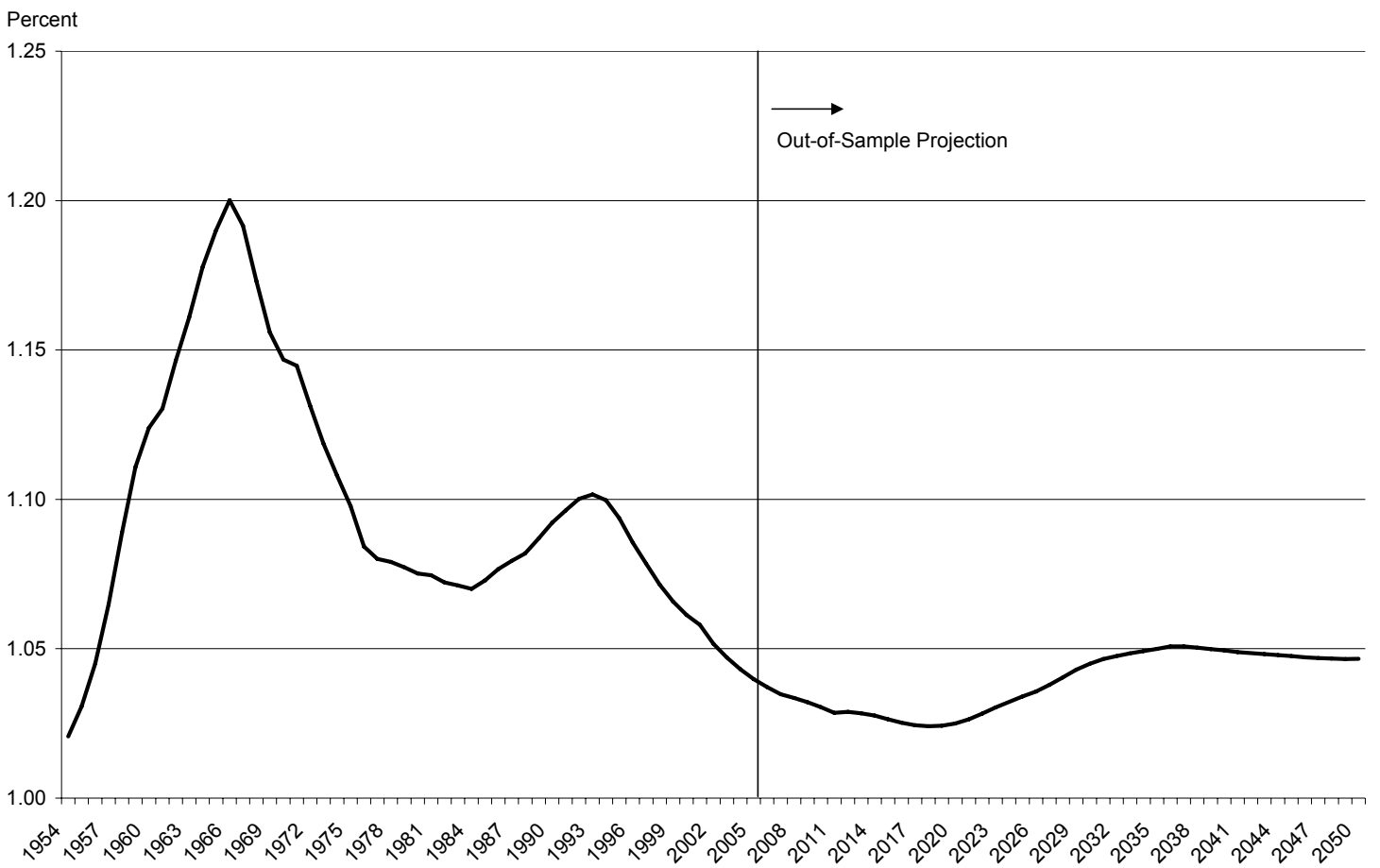

Figure 10. 10 Year Real T-Bill Rate Vs. Model Real Ten Year

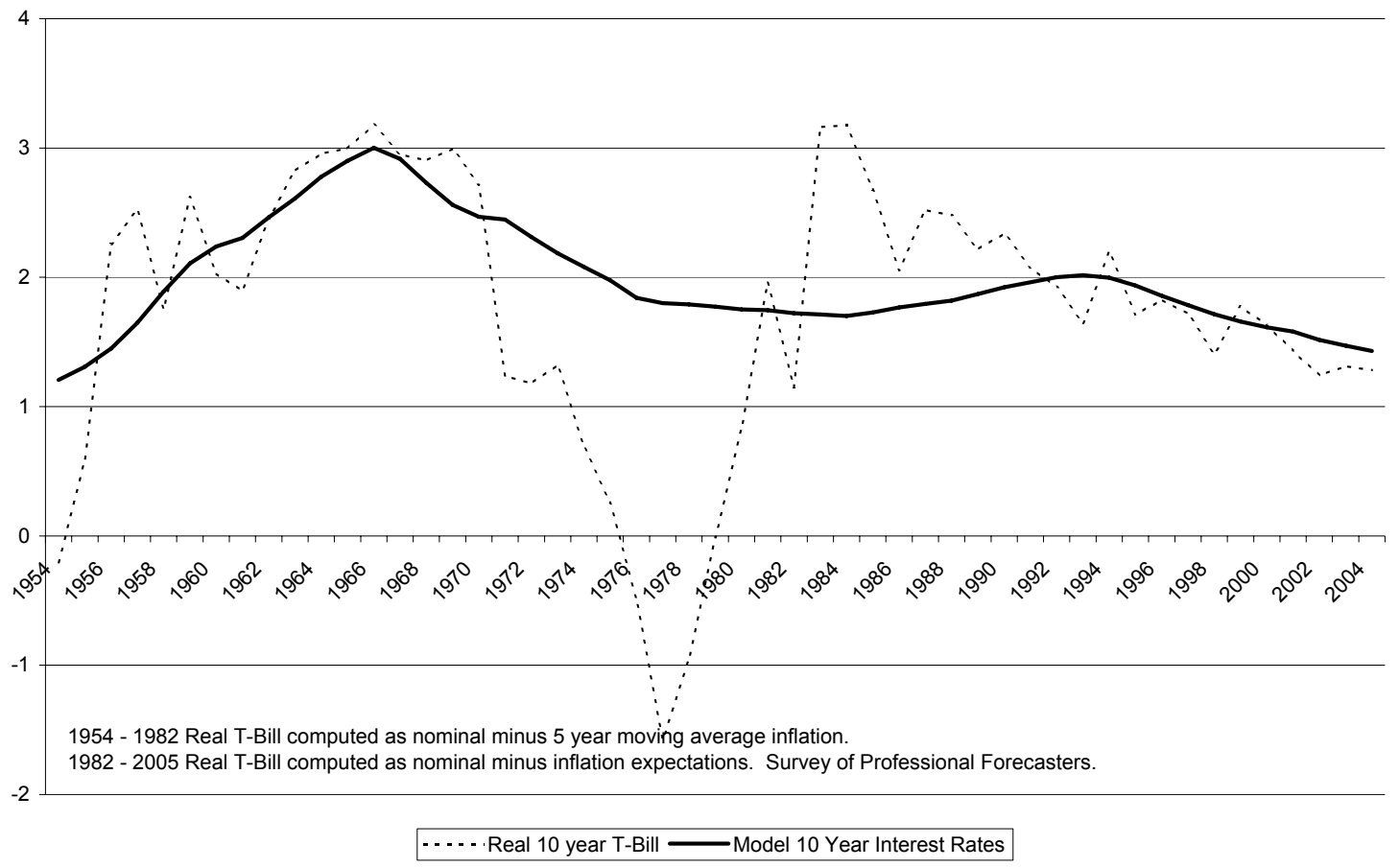


Figure 11. Short-Term Real Interest Rate

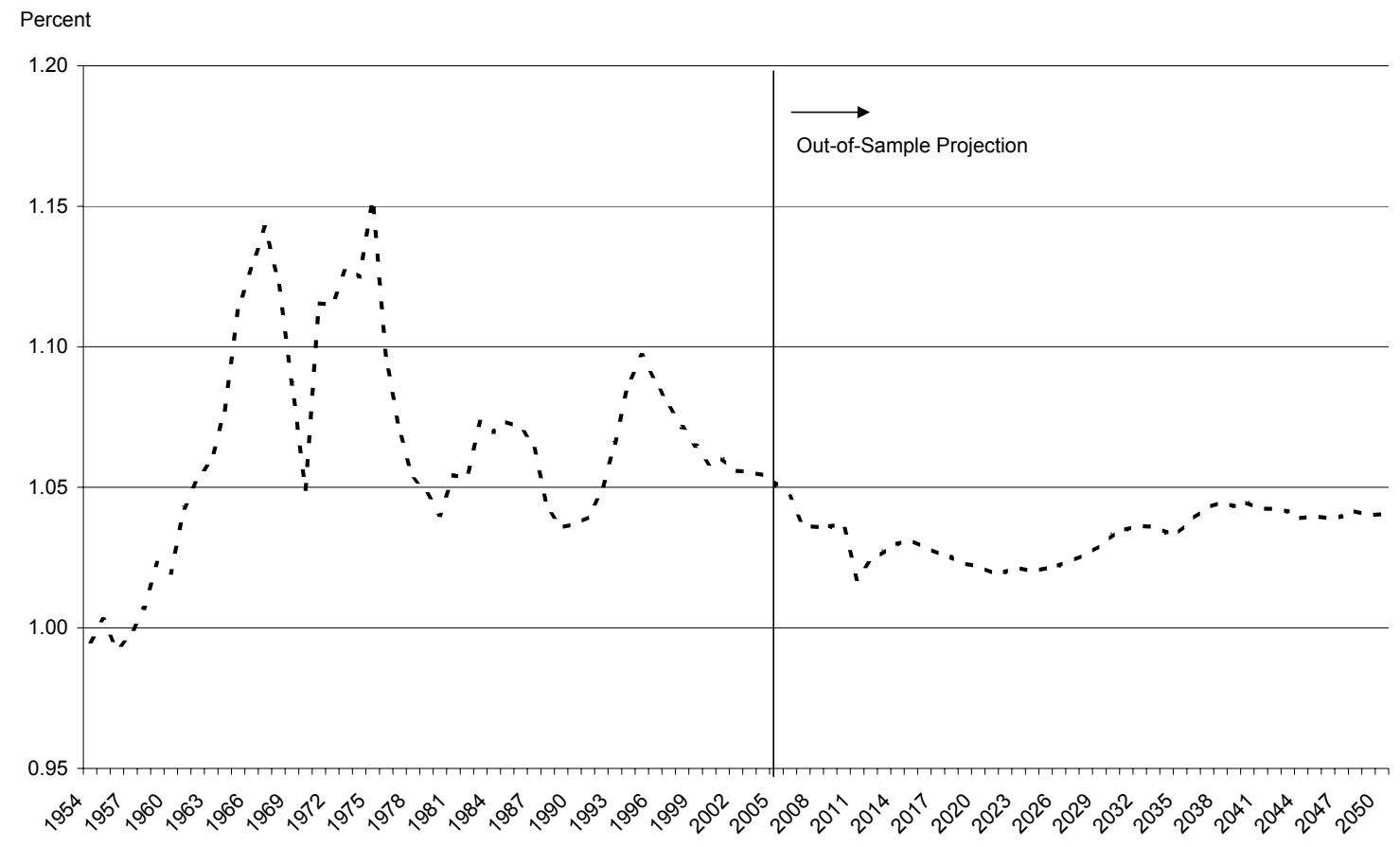

Figure 12. Macroeconomic Volatility

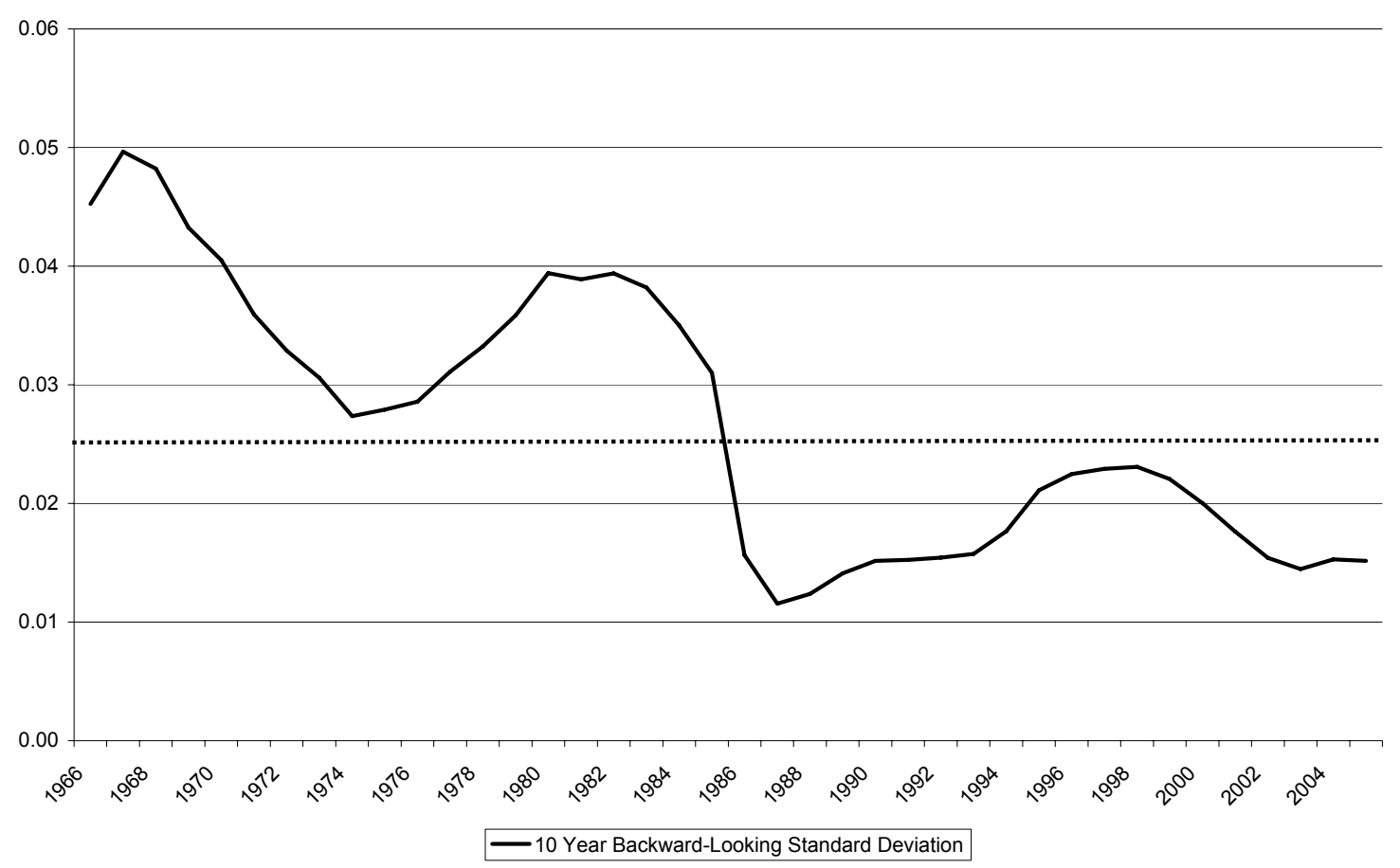


Figure 13. Japan: Simulated and Real House Prices

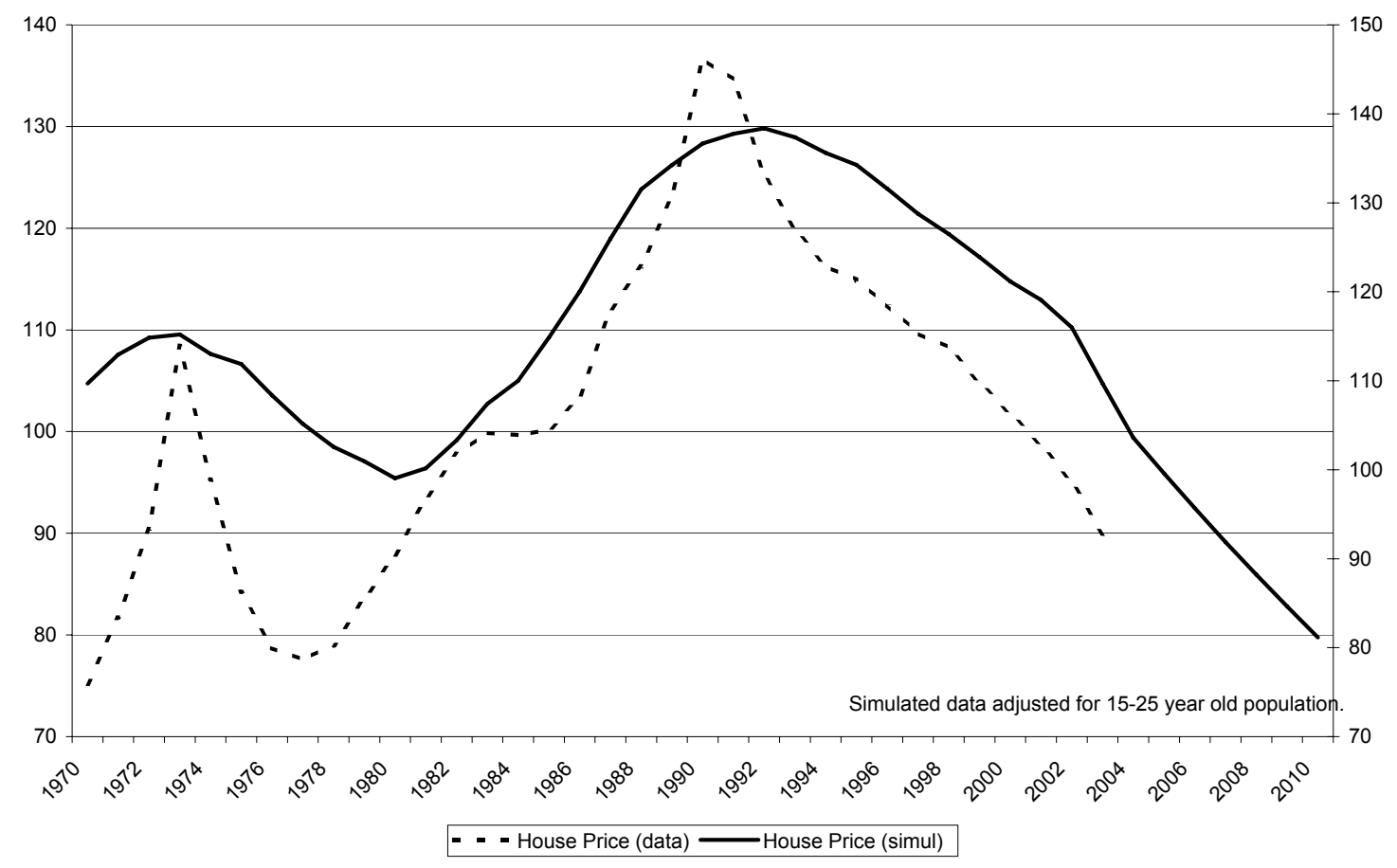

Figure 14. Real House Prices: U.S. vs. U.K.

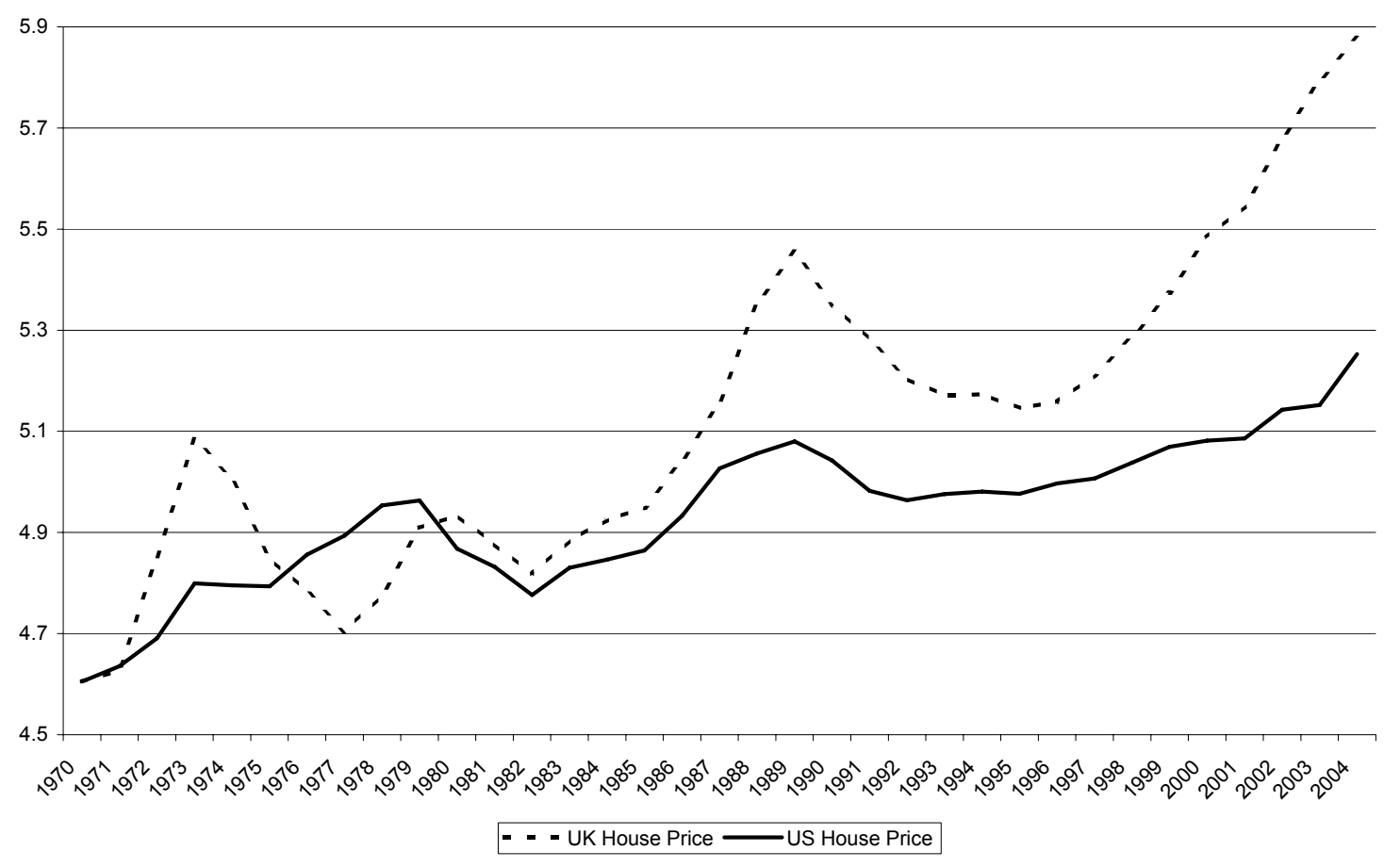

45 


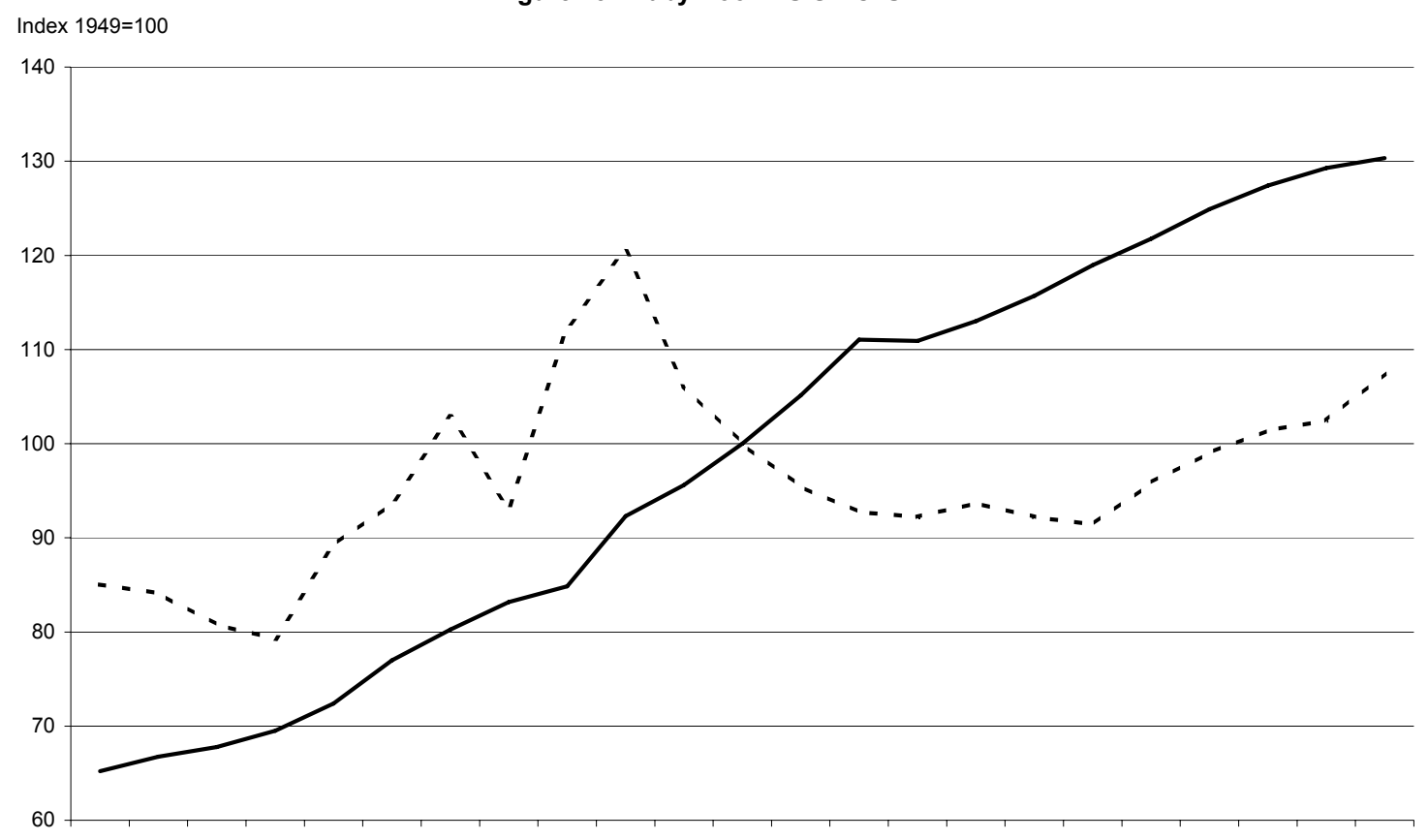

19381939194019411942194319441945194619471948194919501951195219531954195519561957195819591960 - - - Births, UK —Population under age 5, US

Figure 16. United Kingdom: Simulated and Real House Prices

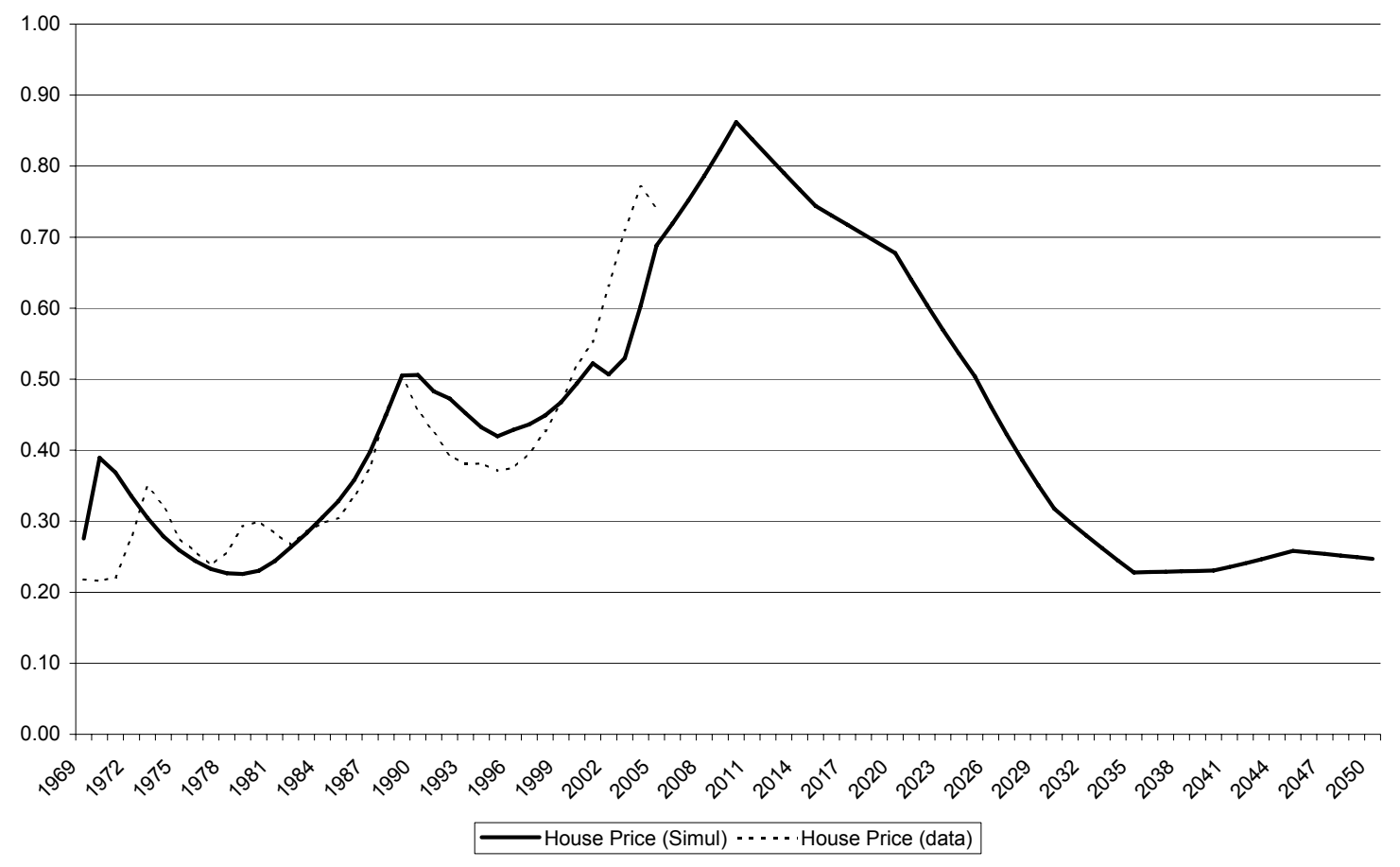


Figure 17. Ireland: Simulated and Real House Prices

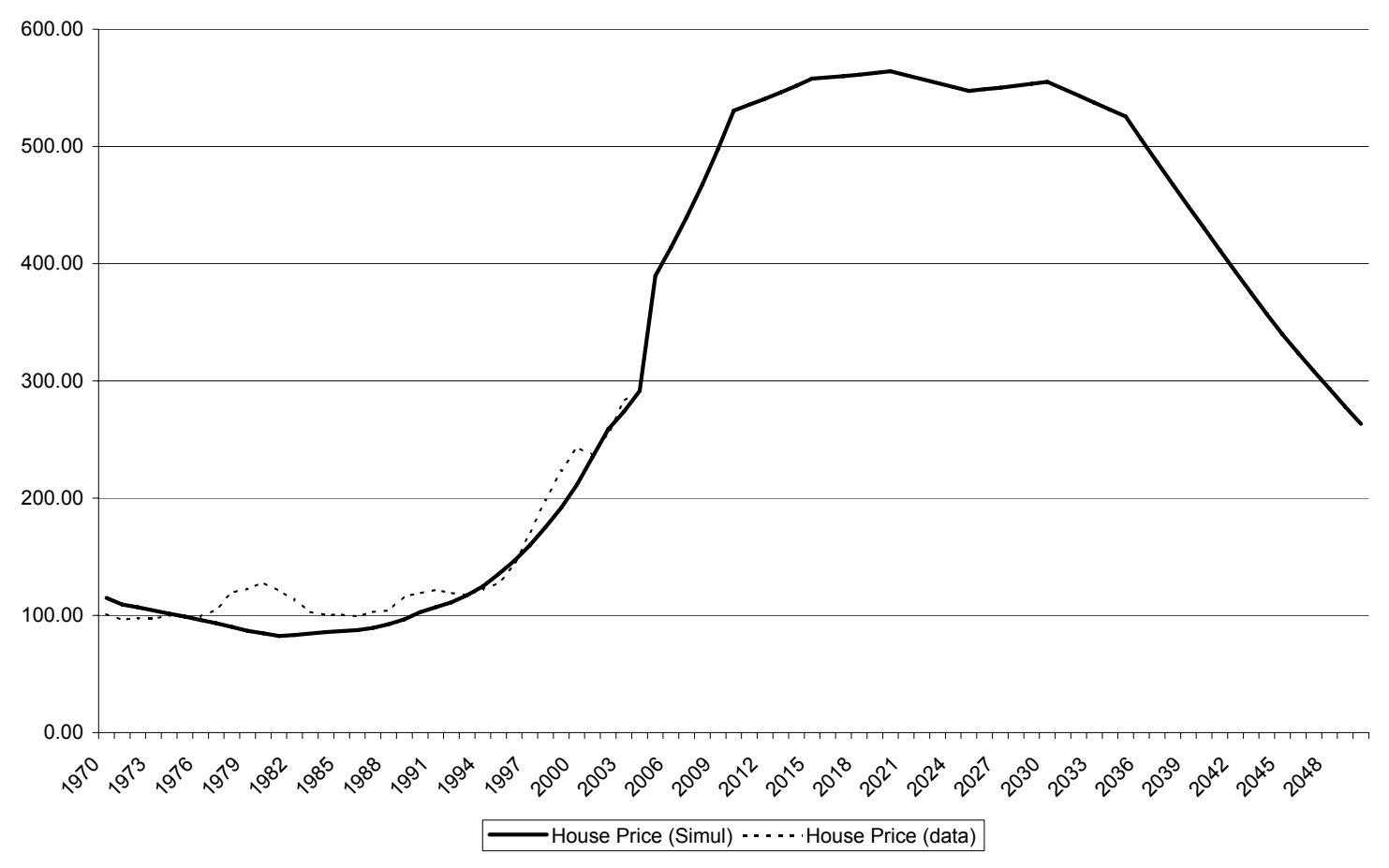

